\title{
A VENTILATION STRATEGY BASED ON CONFLUENT JETS: AN EXPERIMENTAL AND NUMERICAL STUDY
}

SETAREH JANBAKHSH
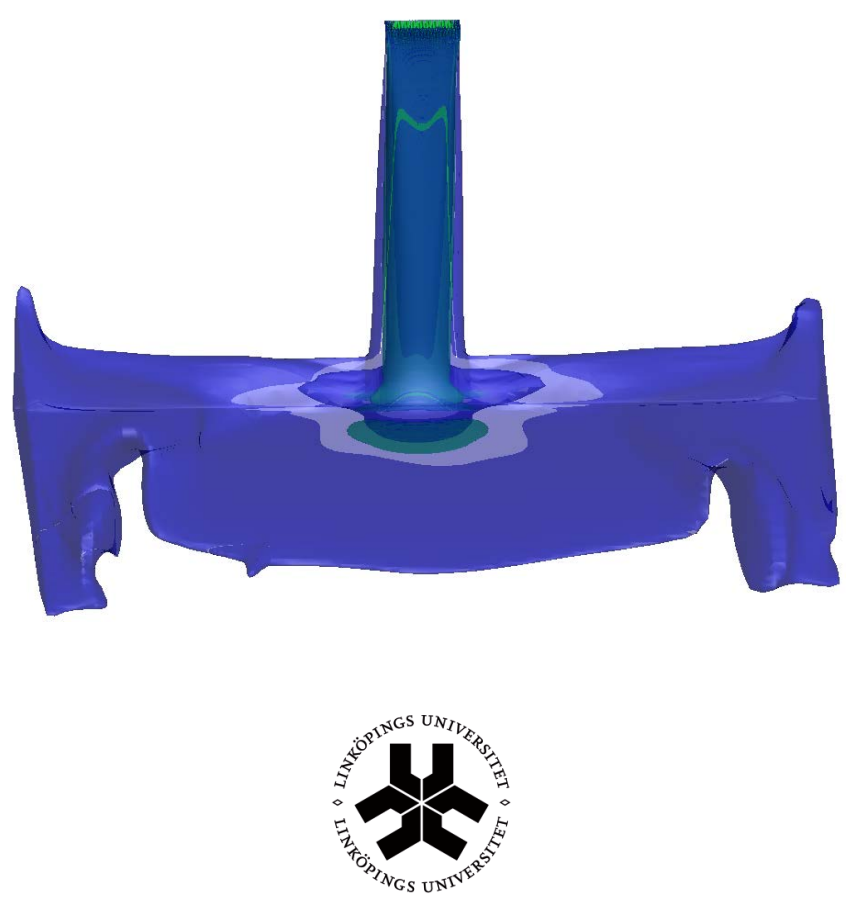

\section{Linköping University}

INSTITUTE OF TECHNOLOGY

Division of Energy Systems

Department of Management and Engineering

Linköping University, SE-581 83 Linköping, Sweden 
Copyright (C) Setareh Janbakhsh, “Unless otherwise noted”.

"A Ventilation Strategy Based on Confluent Jets: An Experimental and Numerical Study"

Linköping Studies in Science and Technology, Dissertation No. 1671

ISBN: 978-91-7519-063-1

ISSN: 0345-7524

Printed in Sweden by LiU-Tryck, Linköping, 2015.

Distributed by:

Linköping University

Department of Management and Engineering

SE-581 83 Linköping, Sweden

Tel: +4613281000 


\section{Abstract}

This study presents air distribution systems that are based on confluent jets; this system can be of interest for the establishment of indoor environments, to fulfill the goals of indoor climate and energyefficient usage. The main objective of this study is to provide deeper understanding of the flow field development of a supply device that is designed based on wall confluent jets and to investigate the ventilation performance by experimental and numerical methods. In this study, the supply device can be described as an array of round jets on a flat surface attached to a side wall. Multiple round jets that issue from supply device apertures are combined at a certain distance downstream from the device and behave as a combined jet or so-called confluent jets. Multiple round jets that are generated from the supply device move downward and are attached to the wall at the primary region, due to the Coanda effect, and then they become wall confluent jets until the floor wall is reached. A wall jet in a secondary region is formed along the floor after the stagnation region.

The characteristics of the flow field and the ventilation performance of conventional wall confluent jets and modified wall confluent jets supply devices are investigated experimentally in an office test room. The study of the modified wall confluent jets is intended to improve the efficiency of the conventional wall confluent jets while maintaining acceptable thermal comfort in an office environment. The results show that the modified wall confluent jets supply device can provide acceptable thermal comfort for the occupant with lower airflow rate compared to the conventional wall confluent jets supply device.

Numerical predictions from three turbulence models (renormalization group (RNG $k-\varepsilon$ ), realizable $(\operatorname{Re} k-\varepsilon$ ), and shear stress transport (SST $k-\omega)$ ) are evaluated by measurement results. The computational box and nozzle plate models are used to model the inlet boundary conditions of the nozzle device. In the isothermal study, the wall confluent jets in the primary region and the wall jet in the secondary region, when predicted by the three turbulence models, are in good agreement with the measurements. The non-isothermal validation studies show that the SST $k-\omega$ model is slightly better at predicting the wall confluent jets than the other two models. The SST $k-\omega$ model is used to 
investigate the effects of the nozzle diameter, number of nozzles, nozzle array configuration, and inlet discharge height on the ventilation performance of the proposed wall confluent jets supply device. The nozzle diameter and number of nozzles play important roles in determining the airflow pattern, temperature field, and draught distribution. Increased temperature stratification and less draught distribution are achieved by increasing the nozzle diameter and number of nozzles. The supply device with smaller nozzle diameters and fewer nozzles yields rather uniform temperature distribution due to the dominant effect of mixing. The flow behavior is nearly independent of the inlet discharge height for the studied range.

The proposed wall confluent jets supply device is compared with a mixing supply device, impinging supply device and displacement supply device in an office environment. The results show that the proposed wall confluent jets supply device has the combined behavior of both mixing and stratification principles. The proposed wall confluent jets supply device provides better overall ventilation performance than the mixing and displacement supply devices used in this study.

This study covers also another application of confluent jets that is combined with impinging technology. The supply device under consideration has an array of round jets on a curve. Multiple jets issue from the supply device aperture, in which the supply device is positioned vertically and the jets are directed against a target wall. The flow behavior and ventilation performance of the impinging confluent jets supply device is studied experimentally in an industrial premise. The results show that the impinging confluent jets supply device maintains acceptable thermal comfort in the occupied zone by creating welldistributed airflow during cold and hot seasons. 


\section{Sammanfattning}

Denna studie behandlar ett luftdistributionssystem som är baserat på confluent jets; ett system som är av intresse vid upprättande av inomhusmiljöer för att uppnå målsättningen för inomhusklimat och energieffektivitet. Huvudmålen för denna studie är att tillhandahålla information om strömningsbilden från ett tilluftsdon som utformats utifrån väggsamverkande strålar (wall confluent jets) och att undersöka ventilationsprestanda med experimentella och numeriska metoder. I den här studien kan tilluftsdonet beskrivas som en uppsättning av runda strålar på en platt yta, som är installerad på en sidovägg. Multipla runda strålar som utgår från öppningar i tilluftsdonet sammanfaller på ett visst avstånd nedanför donet och beter sig som en enda jetstråle eller så kallade confluent jets. Multipla runda strålar som genereras från tilluftsdonet, rör sig nedåt och klistrar sig på vid väggen (ett primärområde) beroende på Coanda-effekten; de blir sedan väggsamverkande strålar innan de når golvytan. En väggstråle bildas i ett sekundärt område längs golvet efter stagnations-området.

Flödesfältets egenskaper och ventilationsprestanda hos tilluftsdon för konventionella väggsamverkande strålar och don för modifierade väggsamverkande strålar har undersökts experimentellt i ett kontrollerat kontorsrum. Studien av de modifierade väggsamverkande strålarna är avsedd att öka effektiviteten hos det konventionella donet samtidigt som man har acceptabla termiska förhållanden i kontors-miljön. Resultatet visar att det modifierade tilluftsdonet kan ge både behaglig termisk komfort i vistelsezonen och även göra det med mindre luftflöde jämfört med det konventionella tilluftsdonet.

Numeriska förutsägelser gjorda med tre turbulensmodeller (renormalization group (RNG $k-\varepsilon$ ), realizable (Re $k-\varepsilon$ ), och shear stress transport (SST $k-\omega$ )) har utvärderats mot mätresultat. Modellerna för beräkningsboxen och munstyckesplattan har använts för att utforma själva intaget i munstycket. I den isotermiska studien, visar de väggsamverkande strålarna i primärområdet och vägg-strålarna i det sekundära området god överensstämmelse med mätningarna, när de utvärderades med hjälp av de tre turbulens-modellerna. De ickeisotermiska valideringsstudierna visar att SST $k-\omega$ modellen är något bättre på att prediktera de väggsamverkande strålar än de andra två 
modellerna. SST $k-\omega$ modellen används för att undersöka effekterna av munstyckets diameter, antalet mun-stycken, munstyckesutformningen, och donets inverkan på ventilation-sprestanda hos det föreslagna confluent jet-tilluftsdonet. Munstyckets diameter och antalet munstycken har stor betydelse för bedömningen av luftströmningens utformning, temperaturfältet och förekomsten av drag. Ökad temperatur-stratifiering och mindre förekomst av drag uppnås med ökad munstyckesdiameter och fler munstycken. Tilluftsdon med mindre munstyckesdiameter och färre munstycken ger ganska enhetlig temperaturstratifiering beroende på den dominerande omblandade effekten. Flödets beteende är nästan oberoende av höjden på donet inom det studerade området.

Det föreslagna tilluftsdonet för väggsamverkande strålar jämförs med ett omblandande tilluftsdon, ett impinging tilluftsdon och ett deplacerande don. Resultaten visar att det föreslagna tilluftsdonet för väggsamverkande strålar kombinerar egenskaperna för omblandande och stratifierande principer. Det föreslagna tilluftsdonet för väggsamverkande strålar erbjuder generellt bättre ventilations-prestanda än de omblandande och stratifierande tilluftsdonen som användes i denna studie.

Studien omfattar även en annan applikation av confluent jets som är baserad på impinging teknologi. Det studerade tilluftsdonet har en uppsättning av runda strålar placerade i en båge. Multipla strålar utgår från donets öppning, där donet sitter vertikalt och strålarna riktas mot en bestämd vägg. Flödesbeteendet och ventilationsprestanda hos tilluftsdonet med impinging confluent jets studeras experimentellt $i$ en industriell lokal. Resultaten visar att tilluftsdonet med impinging confluent jets kan bevara acceptabel termal komfort i vistelsezonen genom att skapa ett välfördelat luftflöde under både varma och kalla årstider. 


\section{List of publications}

This thesis is based on the following research papers:

Paper I: Janbakhsh, S., Moshfegh, B., 2009. Experimental investigation of a new supply diffuser in an office room, Proceedings of 11th International Conference on Air Distribution in Rooms. (ROOMVENT), Busan, Korea.

Paper II: Janbakhsh, S., Moshfegh, B., 2014. Experimental investigation of a ventilation system based on wall confluent jets. Building and Environment 80, 18-31.

Paper III: Janbakhsh, S., Moshfegh B., 2014. Numerical study of a ventilation system based on wall confluent jets. HVAC\&R Research, 20, 846-61.

Paper IV: Janbakhsh, S., Moshfegh B., 2015. Investigation of design parameters for an air supply device based on wall confluent jets. Submitted to journal for publication.

Paper V: Chen, H., Janbakhsh, S., Larsson, U., Moshfegh, B., 2015. Numerical investigation of ventilation performance of different air supply devices in an office environment. Building and Environment 90, 37-50.

Paper VI: Janbakhsh, S., Moshfegh, B., Ghahremanian, S., 2010. A newly designed supply diffuser for industrial premises. International Journal of Ventilation, 9, 59-68.

The following paper was published during my $\mathrm{PhD}$ but it is not included in this thesis.

Janbakhsh, S., Moshfegh, B., 2010. Takaseinäpuhallusjärjestelmän tehokkuus toimistotilassa-matemaattisia ja kokeellisia tutkimuksia, Sisäilmastoseminaari ISBN 978-952-5236-37-8/ISBN 1237-1866, Espoo, Finland, pp. 67-72.

Moshfegh, B., Janbakhsh, S., 2010. On the performance of a new ventilation strategy for office space, World Renewable Energy Congress XI, Abu Dhabi, UAE, pp. 674-679. 


\section{Acknowledgmens}

I would like to thank my supervisor, Professor Bahram Moshfegh, for introducing me to the world of scientific research and for all of his support, guidance, advice, and trusting me as an independent researcher during my work in the past few years.

This thesis has been proofread by Dr. Shahriar Ghahremanian and Assistant Professor Mathias Cehlin, their feedbacks and useful comments are very much appreciated. I would like to thank Associate Professor Taghi Karimipanah for all of his kind advices and comments on my papers and thesis. I would like to thank Professor Hazim Awbi for constructive discussions on my research. The author is thankful for the assistance of Tech.lic. Hans Lundström in the laboratory work.

I would also like to thank Tech.lic. Ulf Larsson, Mr. Staffan Nygren, Dr. Claes Blomqvist, Mrs. Eva Wännström and many others from the University of Gävle. I would like to thank the former and present doctoral students, Helena, Ebbe, Amir, Mohammad, Marita, Abolfazl, Ali, Alan, Gottfried and Jessika, and I will never forget our conservations during lunch and fika time. I also want to thank PhD student Klas Svensson at Linköping University.

I would like to thank and gratefully acknowledge the financial support from the University of Gävle (Sweden), Stravent Oy (Finland), especially Mr. Timo Karkulahti and Sparbankensstiftelse Nya.

My family and friends all over the world, especially my mom, Mahin, and my dad, Mostafa, for their dedication, great patience, unconditional love, and encouragement; my brother, Payman; sisters, Sanaz and Sadaf; my brother-in-law Reza, my sister-in-law Nieves; and my in-law family (Hossein (may he rest in peace), Homa, Shahrzad, Shayan and Mohammad) for their continuous support and encouragement.

To my loved ones, my dear Shahriar and our lovely son Arwin. Shahriar, I am forever thankful that you have come into my life of more than two decades with endless love and to standing beside me during the hardest moments of my life. Shahriar, true love of my life, thanks for generous support, incredible patience and positive encouragement. I will truly miss these days when we were classmates, colleagues, experimental collaborators, and officemates. My dear Shahriar, your scientific contributions to this thesis are countless and invaluable and have made the entire thesis possible. My adorable son, Arwin, for showing me a real sense of joy in life. Thanks for accompanying me through this journey; you have given me endless energy to complete this study. 


\section{Nomenclature}

\section{Symbol}

A

$A_{n}$

c

$d$

$f_{c l}$

$h_{c}$

$H$

$I_{c l}$

g

L

l

$\mathrm{M}$

$M_{r}$

$P_{a}$

Q

$r$

T

$\mathrm{Tu}$

$t_{c l}$

$\overline{t_{r}}$

$U$

u

V

v

W

$W_{e}$
Description

area

total area of the nozzles

number of column

diameter of the nozzle

clothing area factor

convective heat transfer coefficient

height of the test room

clothing insulation

gravity

length of the test room

length scale

measurement

Metabolic rate

water vapour pressure

supply airflow rate

number of row

temperature

turbulence intensity

clothing surface temperature

mean radiant temperature

mean velocity

velocity in $x$-direction

room volume

velocity in $y$-direction

width of the test room

effective mechanical power
Unit

$\mathrm{m}^{2}$

$\mathrm{m}^{2}$

$\mathrm{mm}$

$\mathrm{W} / \mathrm{m}^{2 \circ} \mathrm{C}$

$\mathrm{m}$

$\mathrm{m}^{2 \circ} \mathrm{C} / \mathrm{W}$

$\mathrm{m} / \mathrm{s}^{2}$

m

m

$\mathrm{W} / \mathrm{m}^{2}$

$\mathrm{Pa}$

$\mathrm{m}^{3} / \mathrm{s}$

${ }^{\circ} \mathrm{C}$

$\%$

${ }^{\circ} \mathrm{C}$

${ }^{\circ} \mathrm{C}$

$\mathrm{m} / \mathrm{s}$

$\mathrm{m} / \mathrm{s}$

$\mathrm{m}^{3}$

$\mathrm{m} / \mathrm{s}$

m

$\mathrm{W} / \mathrm{m}^{2}$ 


\begin{tabular}{lll}
$w$ & velocity in z-direction & $\mathrm{m} / \mathrm{s}$ \\
$x, y, z$ & Cartesian coordinates & $\mathrm{m}$ \\
$z^{*}$ & $1.9-z$ & $\mathrm{~m}$ \\
$v_{a r}$ & relative air velocity & $\mathrm{m} / \mathrm{s}$ \\
$\dot{q}$ & total heat load inside the room & $\mathrm{W} / \mathrm{m}^{2}$ \\
$u_{\tau}$ & friction velocity & $\mathrm{m} / \mathrm{s}$ \\
$y^{+}$ & dimensionless distance from the wall & - \\
Greek & & \\
$\tau_{n}$ & nominal time constant & $\mathrm{s}$ \\
$<\tau>:$ & mean age of air & $\mathrm{s}$ \\
$\varepsilon_{a}$ & air change effectiveness & - \\
$\varepsilon_{t}$ & heat removal effectiveness & - \\
$\theta_{\text {min }}$ & non-dimensional minimum temperature & - \\
$\kappa$ & difference & \\
$\mu$ & von karman constant & - \\
$\mu_{t}$ & dynamic viscosity & $\mathrm{kg} / \mathrm{ms}$ \\
$\mu_{e f f}$ & turbulent viscosity & $\mathrm{kg} / \mathrm{ms}$ \\
$v$ & effective viscosity & $\mathrm{kg} / \mathrm{ms}$ \\
$\rho$ & kinematic viscosity & $\mathrm{m} / \mathrm{s}^{2}$ \\
$\alpha_{k}, \alpha_{\varepsilon}$ & density & $\mathrm{kg} / \mathrm{m}^{3}$ \\
$\sigma_{k}, \sigma_{\varepsilon}, \sigma_{t}$ & inverse effective Prandtl numbers & - \\
$\Theta$ & turbulent Prandtl numbers & - \\
& time average temperature & ${ }^{\circ} \mathrm{C}$ \\
\hline & fluctuating temperature & \\
& &
\end{tabular}

\section{Subscripts}

$\begin{array}{ll}a & \text { air } \\ b & \text { bulk } \\ e & \text { exhaust }\end{array}$




$\begin{array}{ll}i & \text { inlet } \\ l & \text { local } \\ \text { oz } & \text { occupied zone } \\ r & \text { room } \\ s & \text { supply } \\ \max & \text { maximum value } \\ \min & \text { minimum value }\end{array}$

\section{Abbreviations}

$\begin{array}{ll}\text { ADI } & \text { air distribution index } \\ \text { CAV } & \text { constant air volume } \\ \text { CB } & \text { computational box } \\ \text { CJ } & \text { confluent jets } \\ \text { DR } & \text { draught rate } \\ \text { DSD } & \text { displacement supply device } \\ \text { HWA } & \text { hot wire anemometer } \\ \text { HVAC } & \text { heating, ventilation and air conditioning } \\ \text { IHG } & \text { internal heat generation } \\ \text { IJSD } & \text { impinging jet supply device } \\ \text { MSD } & \text { mixing supply device } \\ \text { NP } & \text { nozzle plate } \\ \text { PC } & \text { personal computer } \\ \text { PPD } & \text { predicted percentage dissatisfied } \\ \text { PMV } & \text { predicted mean vote } \\ \text { st } & \text { staggered configuration } \\ \text { VAV } & \text { variable air volume } \\ \text { WCJ } & \text { wall confluent jets } \\ \text { WCJSD } & \text { wall confluent jets supply device }\end{array}$





\section{Table of Contents}

1 Introduction 1

1.1 Motivation for this study 2

1.2 Aims 3

1.3 Research process 3

1.4 Research methods 4

1.5 Limitations 4

1.6 Summary of appended papers 5

$\begin{array}{lll}1.7 & \text { Co-author's statement } & 7\end{array}$

2 Literature review $\quad 9$

2.1 Air distribution systems 9

2.1.1 Mixing ventilation 10

2.1.2 Displacement ventilation 10

2.1.3 Confluent jets (CJ) ventilation 12

2.2 Indoor environment and measures of performance 17

$\begin{array}{ll}\text { 2.2.1 Thermal comfort } & 17\end{array}$

2.2.2 Ventilation effectiveness 19

3 Methods 21

3.1 Experimental techniques 21

3.1.1 Flow visualization and temperature distribution 21

3.1.2 Velocity measurement 21

$\begin{array}{lll}3.1 .3 & \text { Temperature measurement } & 24\end{array}$

3.1.4 Thermal comfort measurement 24

3.2 Computational Fluid Dynamics (CFD) 25

3.2.1 Turbulence 26

3.2.2 Governing equations 26

3.2.3 Computational approaches 27

3.2.4 Boundary conditions 32

3.2.5 Near wall treatments 33

3.2.6 Numerical aspects 33

4 Case studies $\quad 35$

4.1 Office ventilation 35

4.1.1 Conventional WCJ supply device 36

4.1.2 Modified WCJ supply device 39 
4.2 Industrial ventilation: ICJ supply device 44

5 Results and discussion $\quad 47$

5.1 Experimental study $\quad 47$

$\begin{array}{lll}5.1 .1 & \text { Office ventilation } & 47\end{array}$

5.1.2 Industrial ventilation 50

5.2 Numerical study 52

5.2.1 Validation study 52

5.2.2 Parametric study 57

5.2.3 Comparison study 61

6 Conclusions $\quad 65$

$\begin{array}{lll}7 & \text { Suggestions for future work } & 67\end{array}$

$\begin{array}{ll}\text { References } & 69\end{array}$ 


\section{Introduction}

During the past two decades, the global demand for energy has doubled, while the demand for electrical energy has tripled. The goal of the EU is to reduce energy use by over $80 \%$ by 2050 . The EU Commission has started to work on reduce energy use and greenhouse gas emissions by 20\% by the year 2020 (Sayigh, 2013; Zhivov et al., 2014). In Sweden, the Environmental Advisory Council has stated that the demand for purchased energy in the building sector should decrease by at least $30 \%$ by 2025 compared to 2000 . The proportion of energy usage in the building sector is larger than that used in transport or industrial processes in developed countries (Awbi, 2003). The energy demand in the built environment is a growing issue, and in Sweden, the building sector accounts for almost $35 \%$ of the total energy use and $15 \%$ of the total $\mathrm{CO}_{2}$ emissions (Sayigh, 2013).

Since the energy crisis of the mid-1970s, energy-saving measures have been required to reduce energy use in the heating and cooling of buildings. Attempts have been made to find a balance between the air distribution, thermal comfort, indoor air quality and energy usage. Therefore, it is vital to select appropriate measures to reduce the energy usage in building environments. One measure to reduce the use of energy is the use of air-tight building facades. Building with more air-tight envelope causes indoor air quality and health issues to emerge, and there is a consequent loss of productivity (Cao et al., 2014).

Currently, most people spend the majority of their time indoors. This highlights the importance of well-functioning heating, ventilation and air conditioning (HVAC) systems. A ventilation system is a process of transporting outdoor air into a building, distributing air to different rooms, and finally moving the air out of the building. The main purpose of ventilation systems within the building environment is to provide thermal comfort and air quality, which must be considered in the design 
of a ventilation system for a building. Poor or uncomfortable indoor conditions cost large amounts of money, in terms of, for example, healthcare, lost productivity, and reduced performance in offices and classrooms (Fanger, 2000; Fisk and Rosenfeld, 1997; Wargocki 1998). Thermal and air quality are two factors that are related to both energy usage and the health of the occupants. Thus, a proper ventilation system is needed to fulfill the goals for indoor climate and energy use.

\subsection{Motivation for this study}

As described in the above section, the ventilation system that is installed in a building is an important component of energy usage and for maintaining a healthy indoor environment with an adequate supply of fresh air. It is of great importance to develop a ventilation system that improves the thermal comfort of the occupants and the ventilation efficiency. Extensive research has been conducted to determine the ventilation performance of the most common air distribution systems, such as mixing and displacement. These systems, despite their large market share, have some limitations and disadvantages. Conventional mixing ventilation has a low ventilation effectiveness and air exchange efficiency (Etheridge and Sandberg, 1996). Displacement ventilation provides a high air-exchange efficiency and ventilation effectiveness (Mathisen HM., 1989; Palonen et al., 1991) and has an energy saving potential compared to a mixing ventilation (Cao et al., 2014). Moreover, in displacement ventilation, air might not spread to a farther distance in a room and is limited to use in a cooling mode (Karimipanah et al., 2007). To overcome the problems of mixing and displacement systems, air distribution systems based on confluent jets (CJ) are studied to provide some of the positive effects of both displacement and mixing systems. To the author's knowledge, the wall confluent jets (WCJ) system has not been extensively investigated in an indoor environment. Impinging confluent jets (ICJ) system has also been investigated in a few studies; therefore, a deeper understanding of the WCJ and ICJ ventilation is key to improving the efficiency of a system and to providing an acceptable indoor environment. 


\subsection{Aims}

The main aim of this study is to gain a thorough understanding of the flow behavior of an air distribution system that is based on WCJ in an indoor environment. The primary objective of the study is to investigate the flow field, temperature distribution and ventilation performance (in terms of the thermal comfort and ventilation efficiency) of WCJ supply devices in an office environment by experimental and numerical methods. One of the objectives of the numerical study is to validate the performance of various turbulence models and to choose a reliable turbulence model for parametric studies. The study of varying designs of configuration WCJ devices is intended to improve the efficiency of the system while providing acceptable thermal comfort in an office environment. The aim of the study of WCJ supply device is also to compare it with other common air distribution systems with respect to the thermal comfort, ventilation efficiency and energy-saving potential. This study also aims to experimentally investigate the flow field, temperature distribution and ventilation performance of ICJ in an industrial premises.

\subsection{Research process}

This thesis is based on four research processes: experimental study, numerical study, parametric study and comparison study. First, the ventilation performance of WCJ is experimentally investigated in a test room and ICJ in an industrial premises (Papers I and VI). To improve the efficiency of the system, the WCJ supply device is then modified and analyzed experimentally in the same test room (Paper II). Because the measurements are limited to various locations and cases, numerical simulations are performed for a detailed study; this approach allows us to present the aspects that are not measured, such as the mean age of the air. The numerical simulations are compared and validated with the measurement data (Papers III and IV). In the second part, based on the model that is validated, the important variables are identified and the impact of different configurations of the modified WCJ supply device on the ventilation performance is examined in terms of the thermal comfort and ventilation efficiency (Papers III and IV). Finally, numerical simulations are performed to compare the ventilation performance of the 
proposed WCJ supply device with mixing, displacement and impinging jet supply devices (Paper V).

\subsection{Research methods}

Two main scientific research methods are used in this study, measurement and numerical simulation (i.e., Computational Fluid Dynamics (CFD)). The measurements (such as visualization and pointmeasuring methods) are performed to understand the flow field, temperature distribution and characteristics of a WCJ ventilation and to evaluate different turbulence models and to provide boundary conditions for the numerical prediction of the flow. Numerical simulation (CFD) using Reynolds Average Navier-Stokes (RANS) equations is employed for turbulence modeling, which is validated by detailed flow and temperature measurements, and this approach allows us to reach a deeper understanding of the characteristics of a WCJ system (which is costly to be explored from the measurements alone). Finally, the validated turbulence model is used to perform an extensive parametric study for the purpose of investigating the influence of the varying designs of wall confluent jets supply device on ventilation performance and to compare this device with different air distribution systems. The measurements are also used to investigate the flow and temperature fields and the ventilation performance of the ICJ ventilation.

\subsection{Limitations}

The experimental investigation of WCJ is limited to the velocity, temperature, and thermal comfort measurement. The measurements of the flow are limited to one-dimensional hot wire and omnidirectional hotsphere anemometers. The investigation of the WCJ ventilation is limited to the cooling mode in the office environment. The configuration of the WCJ supply device (i.e., the diameter, number of nozzles, spacing between nozzles and nozzle array configuration) is kept constant during the measurement. The numerical simulation is limited to steady-state two-equation eddy viscosity turbulence models due to computational resources. The validation study is limited to a certain number of locations. The parametric study considered the effects of change on one parameter at a time. The comparison of different air distribution system is 
limited to numerical simulations, specific room conditions and certain types of air supply devices. The study of ICJ ventilation is limited to experiments in industrial premises, with a focus on the velocity, temperature and thermal comfort.

\subsection{Summary of appended papers}

The thesis is based on the following papers:

Paper I: Janbakhsh, S., Moshfegh, B., 2009. Experimental investigation of a new supply diffuser in an office room, Proceedings of 11th International Conference on Air Distribution in Rooms. (ROOMVENT), Busan, Korea.

In this paper, the air distribution system that is based on WCJ is experimentally studied. The WCJ is described as a number of free circular jets that issue from different apertures at the inlet of the supply device, which is covered by a convex perforated plate. A set of measurements are performed in a mock-up office environment, with a focus on the velocity and temperature measurement below the supply device and in the room with a thermistor, a one-dimensional hot wire, and omnidirectional hot-sphere anemometers. The temperature distribution were explored by means of infrared camera imaging. Thermal comfort indices (i.e., predicted mean vote (PMV) and predicted percentage dissatisfied (PPD)) and draught rate (DR) are evaluated in the middle of the room and in various zones at four heights.

Paper II: Janbakhsh, S., Moshfegh, B., 2014. Experimental investigation of a ventilation system based on wall confluent jets. Building and Environment 80: 18-31.

In this paper, the performance of the modified WCJ supply device is investigated experimentally in a mock-up office environment. A modified WCJ supply device can be described as multiple round jets that issue from supply device apertures. The velocity and temperature fields are studied below the supply device (primary jet region) and along the floor (secondary jet region) using a one-dimensional hot wire and omnidirectional hot-sphere anemometers. The self-similarity characteristics of the temperature and velocity profiles are observed in the primary jet region. The PMV, PPD and DR are also evaluated via the 
mean velocity, turbulence intensity, temperature and humidity in the test room.

Paper III: Janbakhsh S, Moshfegh B., 2014. Numerical study of a ventilation system based on wall confluent jets. $H V A C \& R$ Research, 20: 846-61.

The numerical investigation of the airflow pattern created from the isothermally modified WCJ supply device is presented in a ventilated room. The box method is used to specify the inlet boundary conditions. The numerical predictions of the renormalization group $k-\varepsilon$, realizable $k-\varepsilon$ and shear stress transport $k-\omega$ models are compared with the detailed measurements from Paper II. The velocity decay and spreading rate of the jet are also compared with the experimental results from the literature. The effect of the inlet discharge height and inlet airflow rate are investigated numerically by the renormalization group $k-\varepsilon$ on the vertical and lateral spreading of the wall jet and the decay of the maximum velocity of the wall jet across the floor.

Paper IV: Janbakhsh S., Moshfegh B., 2015. Investigation of design parameters for an air supply device based on wall confluent jets. Submitted to journal for publication.

Numerical investigations of a modified WCJ supply device are presented for the renormalization group $k-\varepsilon$, realizable $k-\varepsilon$, and shear stress transport $k-\omega$ models. The numerical predictions are validated by measurement data (Paper II) by using the box method and by modeling the supply device as the inlet boundary conditions (NP). The ventilation performance (i.e., thermal comfort, heat removal effectiveness) is numerically investigated by the shear stress transport $k-\omega$ model while varying the design configuration of the air supply device. The configuration of the modified WCJ supply device (i.e., the diameter, number of nozzles, and configuration of the nozzle array) is investigated in detail to explore the proposed WCJ supply device. Finally, the effect of the inlet discharge height is investigated by performing numerical simulations.

Paper V: Chen, H., Janbakhsh, S., Larsson, U., Moshfegh, B., 2015. Numerical investigation of ventilation performance of different air supply devices in an office environment. Building and Environment 90, 37-50. 


\subsection{Co-author's statement}

The ventilation performance of the proposed WCJ supply device (Paper IV) was numerically compared with a mixing supply device, impinging jet supply device, and displacement supply device for the cases that were studied in an office environment. The ventilation performance was discussed in terms of the thermal comfort (PMV, PPD and DR), heat removal effectiveness $\left(\varepsilon_{t}\right)$, air exchange efficiency $\left(\varepsilon_{a}\right)$, and energysaving potential. Cases were studied under identical set-up conditions as well as at the same occupied zone temperature, which was achieved using different airflow rates and adding different heat loads. The energy-saving potential was addressed based on the airflow rates and the related fan power required for each ventilation to achieve a similar occupied zone temperature.

Paper VI: Janbakhsh, S., Moshfegh, B., Ghahremanian, S., 2010. A newly designed supply diffuser for industrial premises. International Journal of Ventilation 9: 59-68.

The characteristics of an ICJ supply device are experimentally investigated in both the heating and cooling seasons inside of industrial premises. The ICJ supply device is described as the jet issue from a number of free circular jets that are fitted on the body of the cylinder. Indoor thermal comfort parameters (i.e., velocity, temperature, PMV, PPD, and DR) are discussed at four different heights above the floor at various locations.

\subsection{Co-author's statement}

The author of this thesis has exclusively conducted all experimental and numerical simulations of the first four papers (I, II, III, and IV) under the supervision of Professor Bahram Moshfegh. The first four papers were written entirely by the author of this thesis. However, valuable comments and advice have been received from Professor Bahram Moshfegh throughout the whole process from planning the investigations, interpreting the results, and finally improvements on the disposition for these papers (I, II, III, and IV). The author of this thesis performed simulations on a wall confluent jets air distribution system for Paper V. The other air distribution systems were simulated by $\mathrm{PhD}$ student Huijuan Chen and the PhD student Ulf Larsson. Paper V was written in collaboration with the first three authors, but Professor Bahram Moshfegh 
contributed with many valuable ideas on formulating the study and important suggestions on the drafts. In Paper VI, the measurements were performed by the first author and $\mathrm{PhD}$ student Shahriar Ghahremanian. The measurement results were analyzed, interpreted and put together by the first author and $\mathrm{PhD}$ student Shahriar Ghahremanian. The first author wrote Paper VI in its entirety. Professor Bahram Moshfegh contributed with valuable comments and advices on the plans and draft of this paper. 


\section{Literature review}

In this chapter, different air distribution systems are discussed while focusing on one recent method of ventilation strategy. The chapter ends by introducing international standards that are used for evaluating the thermal environment and by defining the thermal comfort and ventilation efficiency.

\subsection{Air distribution systems}

Air distribution systems can be divided into different types such as piston, mixing, displacement and hybrid. Characteristic air movement within a space can be described via two main principles of flow patterns: entrainment flow and stratified flow. Entrainment flow is known as mixing. When there is poor mixing in a room, short-circulating flow appears, as a result of leaving much of the supplied air from the room unmixed. Almost no mixing of the room air is achieved in a fully stratified flow (displacement) in the occupied zone, which is desirable for removing pollutants that have been generated in a room. Thus, it is necessary to know the characteristics of the ventilation for the purpose of design, in such a way that the occupants experience good thermal comfort and air quality. Thermal comfort and air quality are indoor environment parameters that are influenced by the air distribution system. An improper selection of the air distribution system can result in an unacceptable velocity, unacceptable temperature gradients and air stagnation in the occupied zone, which could lead to occupier discomfort. Based on the ASHRAE Standard 55 (2004), the occupied zone is generally considered to be the volume between the floor and a height of $1.8 \mathrm{~m}$ from the floor, with a distance of $1.0 \mathrm{~m}$ from the supply device and external wall (opposite wall). The occupied zone has a distance of $0.3 \mathrm{~m}$ from the internal walls. 


\subsubsection{Mixing ventilation}

Mixing ventilation supplies a relatively high velocity to the room and often distributes air via a ceiling supply device (Cao et al., 2010; Lee and Awbi, 2004). A wall jet is generated outside the occupied zone in the upper part of the room. A high degree of mixing is created due to the entrainment of the room air in the supply jet. Mixing systems ideally maintain velocities of less than $0.25 \mathrm{~m} / \mathrm{s}$ in the occupied zone. As a result, a uniform velocity, temperature and contaminant concentration can be achieved throughout the occupied zone. A proper design of a mixing ventilation can be used for cooling and heating as well as ventilation purposes. In this system, above the occupied zone, the concentration levels are lower than within the zone, which results in an overall ventilation efficiency and mean air change effectiveness of less than one (Awbi, 2003; Etheridge and Sandberg, 1996). A mixing ventilation is the most common of the air distribution systems; its various applications have been presented in a guidebook (Müller et al., 2013) and in previous studies (Krajčík et al., 2012; Sandberg et al., 1986). An example of an airflow pattern that was created by mixing can be seen in Figure 1.

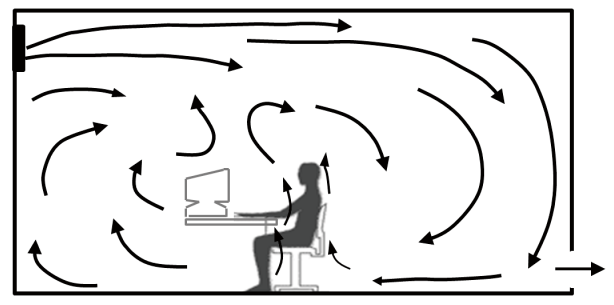

Figure 1. Concept of mixing ventilation.

\subsubsection{Displacement ventilation}

In displacement ventilation, fresh air with a low velocity (typically 0.25 to $0.35 \mathrm{~m} / \mathrm{s}$ ) and a temperature lower than that of the room is supplied at the floor level (Cehlin and Moshfegh, 2010; Karimipanah and Awbi, 2002). Due to having a negative buoyancy effect, the air moves toward the floor after discharge and then spreads across the floor. The air is heated by the heat sources and then moves upward (thermal plumes) in the room and is removed at the ceiling level. Figure 2 shows an example of the air movement in displacement ventilation. This arrangement 
normally create a vertical gradient of air velocity, temperature and contaminant concentration (Goodfellow and Tähti, 2001; Lee and Lam, 2007; Li et al., 1992; Nielsen, 2007; Nielsen, 2000). Displacement ventilation has two distinct zones that form in the room, which are called the lower zone and upper zone. The zone with little or no recirculation (lower zone) has clean and fresh air, while the zone with recirculation (upper zone) is occupied with warm and more contaminant air. The system is a promising ventilation concept due to its high air-exchange efficiency and ventilation effectiveness (Mathisen HM., 1989; Palonen et al., 1991). A limitation in displacement ventilation is that it might not be used for heating purposes (i.e., supplying an air temperature that is higher than the room air temperature). Displacement ventilation has a limited penetration distance in a room that has multiple buoyancy sources. It can be used in a cooling mode because buoyancy is the dominant force that drives air from the floor to the ceiling. Performance of displacement ventilation regards to ventilation efficiency and energy saving can be found in the studies by Causone et al. (2010); Chen and Van Der Kooi (1990); Cheong et al. (2006); Melikov et al. (2005); Nielsen (1993)

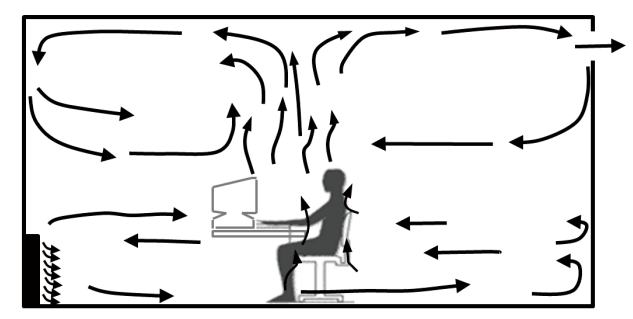

Figure 2. Concept of displacement ventilation.

To overcome the above-mentioned problems, new methods of air distribution have been developed, which are so-called hybrid air distribution systems. Air distribution in hybrid systems is based on high momentum jets. The principle of these air distribution methods is based on the performance of both mixing and displacement air distribution. Confluent jets (CJ) and impinging jet (IJ) are the most promising among these hybrid ventilation (Awbi, 2008). The performance of impinging jet in a ventilated room can be seen in Karimipanah and Awbi (2002). In this thesis, an air distribution system that is based on confluent jets can be found in details. 


\subsubsection{Confluent jets (CJ) ventilation}

Confluent jets can be defined as multiple interacting jets that issue from different nozzles (Awbi, 2003). Typically, the flow field of confluent jets consists of initial, converging, merging and combined regions (Ghahremanian et al., 2014b). The combined jets, after a certain distance from the supply device, behave as a united jet, in which the individual jets can no longer be identified.

The near flow field is complicated for the confluent jets according to the jets' interactions. The flow from an in-line array of multiple interacting jets creates three different confluent jets, i.e., central jets, side jets and corner jets. All of these behave differently in the converged, merged and combined regions in terms of the velocity decay. There is no significant difference between the central, side and corner jets within the initial region. A clear potential core zone can be found within the initial region. The confluent jets start to merge after the converging region. After the nozzle, in the converging region, the side jets curve toward the center of the array. This phenomenon can be seen to be less for the corner jets. The side jets are strongly affected by the neighboring flow compared to the other jets. Due to the deflection, the side jets merge faster compared to the central jets. As a result, the side jets have a shorter potential core, with a faster velocity decay that preserves their maximum velocity less than the corner jets. The combined region is dominated by the potential core, where a small maximum velocity decay can be observed in this region. The contour plot and cross- sectional profiles of the dimensionless mean velocity from an in-line array of round jets, as can be seen in Figure 3 (Ghahremanian et al., 2014a; Ghahremanian et al., 2014b). In a near-field study of multiple interacting jets; confluent jets can be found in detail in the doctoral thesis by Ghahremanian (2014). Different techniques were used for numerical and experimental investigation of the flow behavior of a $\mathrm{CJ}$ in the region close to the nozzle exits (Ghahremanian and Moshfegh, 2014a; Ghahremanian and Moshfegh, 2014b; Ghahremanian et al., 2014a; Ghahremanian et al., 2014b; Svensson et al., 2012; Svensson et al., 2014). 


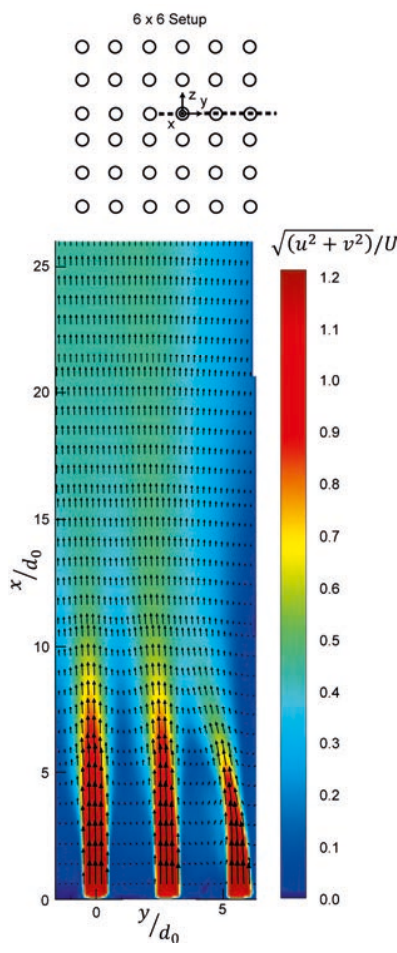

a

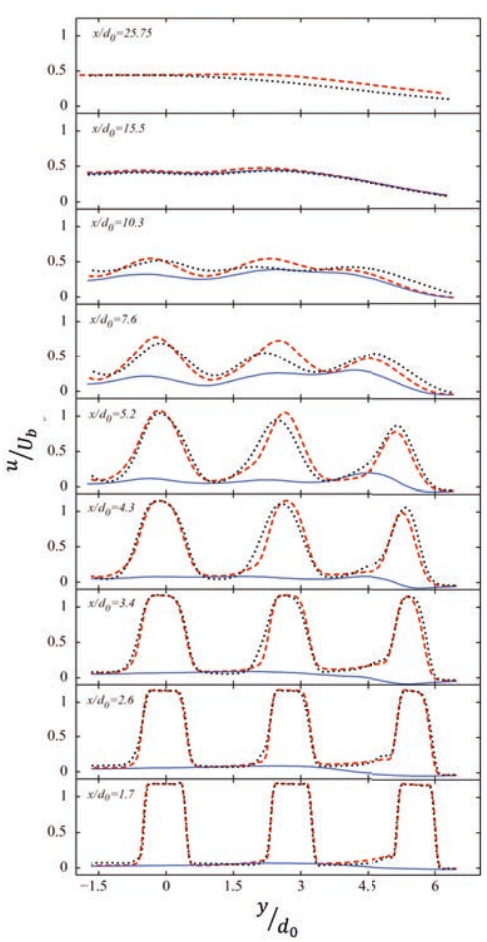

b

Figure 3. Contour plot (a) and cross-sectional profiles (b) of the dimensionless measured velocity from an array of round jets (Ghahremanian et al., 2014a; Ghahremanian et al., 2014b).

\subsubsection{Wall confluent jets}

An air distribution system based on wall confluent jets can be described as a combined jet that issues from the CJ supply device in the vicinity of the wall. The CJ move downward attached to the wall due to the Coanda effect and then becomes a wall jet (Figure 4). An attached wall jet is characterized by the flow being bound on one side by a flat surface and moving parallel to the surface. Upon leaving the nozzle, the jet forms a boundary layer on the wall surface, and a mixing layer develops on the fluid side (Awbi, 2003). The wall jet remains attached to the wall until the floor wall is reached. The free jet region, Coanda effect region, and wall region are three regions of WCJ that were found in the experimental study of a WCJ supply device by Cho et al. (2008). Within 
the free jet region, due to entrainment, the maximum velocity at the jet centerline is higher than that for the near-wall region. In the Coanda effect region, the maximum velocity for the centerline is lower than the maximum velocity for the near-wall region. Within the Coanda effect region, the combined jets behave like a wall jet that has a tendency to attach to the wall, while the confluent pattern also starts from this region onward. The wall region consists of two sub-regions: a wall jet region and an impingement region. In the wall jet region, the decay of maximum velocities is similar for both centerline and near wall regions. However, in the impinging region, the velocity profile is different for the centerline and near wall regions. According to Viets and Sforza (1966), the threedimensional wall jet has three main regions of decay in the maximum velocity along the centerline of the jet, which are called the potential core (core zone) region, characteristic decay (CD) region (transition zone) and radial decay ( $\mathrm{RD}$ ) region (fully established turbulent zone). In the potential core region, the maximum velocity is similar to or very close to the velocity at the nozzle inlet. In the second region (CD), the maximum velocity decays as the constant power of the stream-wise distance. In the radial decay region, the maximum velocity decays like that of a radial wall jet, i.e., "an axisymmetric jet which impinging normally upon a wall and spreads radially over the wall” (Sforza and Herbst, 1970).

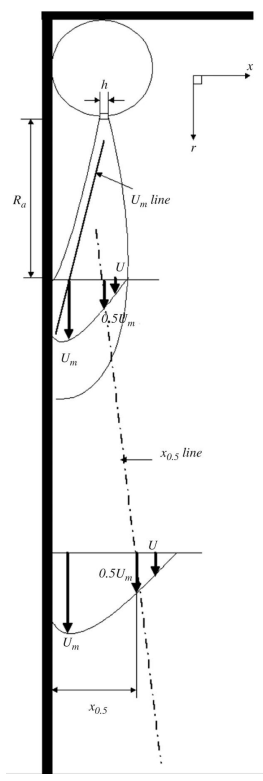

Figure 4. Schematic of wall confluent jets (Cho et al., 2008). 


\subsection{Air distribution systems}

Wall confluent jets have been applied in ventilation only in the studies of Cho et al. (2008) and Karimipanah et al. (2008). Some of the characteristics of the WCJ in their study are described next. It was found that the velocity decay of the WCJ is slower than that of the other jets (e.g., free confluent jets, free plane jet and free plane wall jet). The behavior of this system is such that it leads to slow diffusion due to having a lower rate of velocity decay compared with the free confluent jets, free plane jet and free plane wall jet. In addition, the flow behavior of the WCJ was compared with the displacement system. It was concluded that the WCJ has a greater horizontal spread over the floor than the displacement jet. The WCJ supply device generates a clean air zone in the lower part of the occupied zone. The system has some properties of a mixing system in which the entrainment of the room air in the supply jet occurs. Higher air-change effectiveness can be found compared to a mixing system. The WCJ can eliminate the need for additional heating and cooling systems during cold and hot seasons, compared to a displacement system. The results for the energy performance of the WCJ supply device reveal that this system requires the lowest fan power compared to the displacement, mixing and impinging jet ventilation, to achieve nearly the same value of the air distribution index (ADI) (Awbi, 2003).

\subsubsection{Impinging confluent jets (ICJ)}

The supply device under consideration, namely the impinging confluent jets (ICJ), can be described as multiple jets that issue from the supply device apertures in which the confluent jets supply device is positioned vertically or horizontally and in which the jets are directed against a target wall (Figure 5). The ICJ was studied experimentally and numerically in classrooms for different thermal conditions (Karimipanah et al., 2007). In their study, the ICJ presented slightly better thermal comfort and air quality compared with displacement system. 


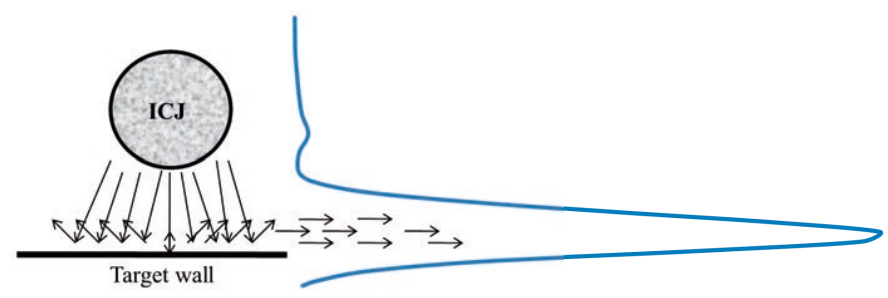

Figure 5. Schematic of ICJ (Janbakhsh et al., 2010).

This thesis addresses the application of WCJ and ICJ, which can be of interest in the design of a ventilation supply device. To the best of the author's knowledge, there are few studies available in the literature that are on air distribution systems based on WCJ and ICJ. 


\subsection{Indoor environment and measures of performance}

Providing a thermal comfort environment and acceptable air quality is one of the important parameters to be considered when designing a ventilation system. The international standards, i.e., ASHRAE standard 55 (2004) and ISO standard 7730 (2005), are mainly standards that were used for evaluating the thermal environment in a test room and industrial building. These two standards are very similar to having the same evaluation methods for PMV (Predicted Mean Vote), PPD (Predicted Percentage Dissatisfied) and local thermal discomfort (e.g., due to draught). The standards mostly use the same recommended criteria. Thermal comfort, air quality and ventilation effectiveness are defined below.

\subsubsection{Thermal comfort}

Thermal comfort is defined in the ASHRAE Standard 55 (2004) as "that condition of mind which expresses satisfaction with the thermal environment". Six environmental factors must be addressed as being important for the thermal comfort definition. These factors are the air temperature, radiant temperature, air speed, humidity, metabolic rate and clothing insulation. The parameters that influence the thermal comfort are incorporated into the comfort equation that was introduced by Fanger P.O. (1973). The values for quantifing the degree of discomfort, i.e. the PMV index, were introduced in equation (1) (ISO 7730, 2005) and are based on tests that were conducted on a group of people according to the psycho-physical (thermal sensation) scale: -3 cold, -2 cool, -1 slightly cool, 0 neutral, +1 slightly warm, +2 warm, and +3 hot (ASHRAE, 2009a; ISO 7730, 2005). PMV is widely used index for calculating the steady state thermal comfort (thermal equilibrium with the environment), which is based on the heat balance of the human body. For an acceptable thermal environment, the PMV value is within the recommended range, or in other words, the conditions are within the comfort zone. 


$$
\begin{aligned}
P M V=[0.303 & \left.\exp \left(-0.036 M_{r}\right)+0.028\right] \\
& \times\left\{\left(M_{r}-W_{e}\right)-3.05\right. \\
& \times 10^{-3}\left[5733-6.99\left(M_{r}-W_{e}\right)-P_{a}\right] \\
& -0.42\left[\left(M_{r}-W_{e}\right)-58.15\right]-1.7 \\
& \times 10^{-5} M_{r}\left(5867-P_{a}\right)-0.0014 M_{r}\left(34-t_{a}\right) \\
& -3.96 \times 10^{-8} f_{c l}\left[\left(t_{c l}+273\right)^{4}-\left(\bar{t}_{r}+273\right)^{4}\right] \\
& \left.-f_{c l} h_{c}\left(t_{c l}-t_{a}\right)\right\}
\end{aligned}
$$

where

$$
\begin{aligned}
& t_{c l}=35.7-0.028\left(M_{r}-W_{e}\right) \\
& -I_{c l}\{3.96 \\
& \times 10^{-8} f_{c l}\left[\left(t_{c l}+273\right)^{4}-\left(\overline{t_{r}}+273\right)^{4}\right] \\
& \left.+f_{c l} h_{c}\left(t_{c l}-t_{a}\right)\right\} \\
& f_{c l}= \begin{cases}1.00+1.290 I_{c l} & \text { for } I_{c l} \leq 0.078 \\
1.05+0.645 I_{c l} & \text { for } I_{c l}>0.078\end{cases} \\
& h_{c}= \begin{cases}2.38\left|t_{c l}-t_{a}\right|^{0.25} & \text { for } 2.38\left|t_{c l}-t_{a}\right|^{0.25}>12.1 \sqrt{v_{a r}} \\
12.1 \sqrt{v_{a r}} & \text { for } 2.38\left|t_{c l}-t_{a}\right|^{0.25}<12.1 \sqrt{v_{a r}}\end{cases}
\end{aligned}
$$

Once the PMV value is calculated, then the PPD index is determined. Fanger P.O. (1973) correlated the percentage ratio of the people who were dissatisfied with the predicted mean vote.

$\mathrm{PPD}=100-95 . \exp -\left(0.03353 P M V^{4}+0.2179 P M V^{2}\right)$

The recommended limits of the PMV and PPD indices, i.e., $-0.5<$ PMV $<0.5$ and PPD $<10 \%$, have been suggested by ASHRAE Standard 55 (2004), while in ISO 7730 (2005), three categories of the thermal environment were suggested (class A category $-0.2<\mathrm{PMV}<0.2$, PPD $<6 \%$; class B category $-0.5<$ PMV $<0.5$, PPD $<10 \%$; and class C category $-0.7<$ PMV $<0.7$, PPD $<15 \%$ ). Because of the accuracy of the instrument, it can be difficult to verify that a PMV is in the class A category.

In ventilated spaces, draught (DR) is defined as a common complain that is associated with the unwanted local cooling of the body caused by air movement. Draught produces a cooling effect of the skin by convection, and the sensitivity to draught increases when the skin is not covered by clothing and people have a low activity level (seatedstanding). The draught sensation depends on the temperature difference 
between the air and the skin, any increase in the air speed and the turbulence intensity in the airflow. This model applies to people in mostly sedentary activity (e.g., an office) and the nearly neutral thermal sensation for the whole body. The percentage of people who feeling draught can be expressed using equation (6) (ASHRAE Standard 55, 2004; ISO 7730, 2005):

$D R=\left(34-T_{a}\right)\left(U_{a}-0.05\right)^{0.62}\left(0.37 U_{a} T u+3.14\right)$

According to the standards of ASHRAE Standard 55 (2004) and ISO 7730 (2005):

For $U_{a}<0.05 \mathrm{~m} / \mathrm{s}$, use $U_{a}=0.05 \mathrm{~m} / \mathrm{s}$.

For $D R>100 \%$, use $D R=100 \%$.

According to ASHRAE Standard 55 (2004), the recommended percentage who are dissatisfied due to draught is less than $20 \%$. In ISO 7730 (2005), draught is restricted to be less than $10 \%, 20 \%$ and $30 \%$ for class categories A, B and C, respectively.

\subsubsection{Ventilation effectiveness}

In a ventilated room, a proper quantity of conditioned air and an effective air distribution is the objective of a ventilation process. This process removes heat and contaminants and creates comfortable conditions with the aim of reducing the operating costs of the ventilation system and air conditioning. The heat removal effectiveness $\left(\varepsilon_{t}\right)$ and contaminant effectiveness $\left(\varepsilon_{c}\right)$ are indices that are used to represent the ability of a ventilation system to remove heat and contaminants, as described in (Awbi, 2003); these indices are expressed as follows:

$\varepsilon_{\mathrm{t}}=\frac{T_{\mathrm{e}}-T_{\mathrm{i}}}{T_{\mathrm{oz}}-T_{\mathrm{i}}}$

$\varepsilon_{\mathrm{c}}=\frac{C_{\mathrm{e}}-C_{\mathrm{i}}}{C_{\mathrm{oz}}-C_{\mathrm{i}}}$

where $T$ and $\mathrm{C}$ are the temperature $\left({ }^{\circ} \mathrm{C}\right)$ and contaminant concentration (ppm), respectively, and the subscripts $e, i$ and oz denote the exhaust, inlet and mean value, respectively in the occupied zone. 
A high value of $\varepsilon_{t}$ and $\varepsilon_{c}$ represent a high performance of the ventilation system in terms of the heat and contaminant removal. To evaluate the indoor environment in the occupied zone, Awbi (2003) and Karimipanah et al. (2008) introduced ADI, which is defined by combining $\varepsilon_{t}$ and $\varepsilon_{c}$ with PPD and $\mathrm{PD}_{\mathrm{AQ}}$ (the indoor air quality index) to represent the perception of thermal comfort and air quality with one parameter (Awbi, 2003).

Sandberg (1981) introduced the concept of the age of air as a tool for evaluating the ventilation effectiveness. The mean age of the air is a measure of the air quality and describes the freshness of the air. The mean age of air is zero through the supply device and increases when the air enters the ventilated space. The room mean air change effectiveness $\left(\varepsilon_{a}\right)$ or so-called air change effectiveness is defined based on the mean age of the air. This index defines how quickly the air in a ventilated space is exchanged with fresh air. Better air quality of the room and a higher exchange efficiency are related to having a lower mean age of air. The air change effectiveness can be used when no information on the contaminants from the source is available. This index is defined by the following expression (Etheridge and Sandberg, 1996):

$\varepsilon_{a}=\frac{\tau_{n}}{2<\tau>}$

where $\tau_{n}(\mathrm{~s})$ is the nominal time constant (the shortest possible air change time, the inverse value of the nominal time constant, is the airexchange rate) for a given room volume, $V\left(\mathrm{~m}^{3}\right)$, the airflow rate, $Q\left(\mathrm{~m}^{3} / \mathrm{s}\right)$, is expressed as $\tau_{n}=V / Q$; and $\langle\tau\rangle$ is the mean age of the air in the room (the actual air change time). 


\section{Methods}

Measurements are used to investigate the performance of the WCJ and ICJ air supply devices; moreover, numerical investigation is used to study the WCJ. Measurement and numerical prediction are employed to present the airflow pattern, temperature distribution, air velocity, air temperature, and turbulence intensity as well as the thermal comfort indices and ventilation efficiency in an indoor environment.

\subsection{Experimental techniques}

\subsubsection{Flow visualization and temperature distribution}

Smoke visualization is the common and simple method of visualizing the air motion in a room. The velocity direction can be estimated by applying a puff of smoke into the flow. Smoke can be produced by the vaporization of paraffin oil in a portable smoke generator. The smoke particles can then be traced and photographed.

An infrared camera provides an image of the temperature distribution of a surface. Previous experimental studies were performed using this technique to capture the temperature field of the jet in a ventilated room (Cehlin et al., 2000; Cehlin et al., 2002; Elvsén and Sandberg, 2009; Sandberg, 2007; Sun and Smith, 2005). Some earlier measurements of the air temperature with this technique were reported by Hassani and Stetz (1994); Stetz (1993); Sundberg (1993).

\subsubsection{Velocity measurement}

Different instruments, such as a Particle image velocimeter (PIV), Laser Doppler anemometer (LDA) and hot wire anemometer, are commonly used to measure the air velocity in an indoor environment. 
These techniques, along with their applications and accuracy, are described in ASHRAE (2009c). PIV measures the fluid velocity by determining the displacement of a group of seeding particles that are introduced into a flow. The advantage of PIV is to examine two-and three-dimensional velocity fields without disturbing the flow field. The PIV technique can be found in detail in Adrian and Westerweel (2010); Raffel et al. (2007). The LDA is an intrusion-free method that also measures one, two and three-dimensional air velocities. The LDA can measure only one point at a time and it performs well at low velocities. In LDA, the velocity measurement is accomplished by determining the frequency shift of the light scattered by moving particles through the intersection volume of two intersecting laser beams. A more comprehensive description of the LDA technique can be found in Boutier (2012). Two types of thermal anemometers for measuring the air velocity at a point in a room are one-dimensional hot-wire anemometer and the omnidirectional hot-sphere anemometer. In this study, the pointmeasuring techniques are based on constant temperature anemometer principle.

\subsubsection{One-dimensional Hot-Wire Anemometry (HWA)}

A Constant temperature hot-wire anemometer consists of a thin tungsten or platinum wire. The sensor is heated electrically and cooled at a specific rate, which is related to the velocity of the fluid. The sensor works based on convective heat transfer from a heated sensor to the surrounding fluid. The heat $q(\mathrm{~W})$ that is exposed to the fluid is equal to $I^{2} R$, where $R$ is the resistance $(\Omega / \mathrm{m})$ and $I$ is the current through the wire. The resistance and temperature of the wire sensor are maintained constant by varying the current, and hence, the current through the wire is a measure of the velocity.

The system consists of a hot wire sensor, constant temperature anemometer module, analog to digital (A/D) converter and computer. Data acquisition, data analysis and applications software for a constant temperature anemometer set-up are part of the system. The constant temperature anemometer signal is obtained via an $\mathrm{A} / \mathrm{D}$ converter board and is saved as a data series in a computer. The output is an analogue voltage, which provides no loss of information. The HWA is simple to use and has high frequency responses (Johnson, 1998; Sandberg et al., 2008), which makes it possible to study turbulent flows. 


\subsection{Experimental techniques}

In the velocity measurement by the hot wire, uncertainty arises mostly from the calibration and, of course, depends on others factors, such as the calibration equipment used, temperature variation of HWA and curvefitting (linearizing) to the calibration results. Contamination of the HWA by dust particles can affect the quality of the velocity measurement results; therefore, the HWA must be recalibrated frequently.

HWA must be calibrated to establish a relationship between the flow velocity and the raw signal output. The calibration must be performed in a low-turbulence flow. Exponential and quartic polynomial functions are used to determine the relationship between the output voltage and the corresponding velocity. The accuracy of the polynomial function arises from more than the exponential function, and more detailed information can be seen in (Bruun, 1995). It is important to calibrate the HWA for the whole range of desired velocities when using the quartic polynomial. Temperature compensation is recommended for correcting the temperature variations.

The HWA must be oriented perpendicular to the incoming flow direction because it is sensitive to the flow direction. It measures only the component of the velocity that is normal to the wire axis; therefore, it is not suitable for measuring the velocity in a room in which the flow directions are unknown. The omnidirectional constant temperature anemometer will be more suitable for measuring the velocity in a room. The one-dimensional hot-wire anemometer was used e.g., in the study of confluent jets (Ghahremanian and Moshfegh, 2014a; Ghahremanian and Moshfegh, 2014b) and displacement ventilation (Cehlin and Moshfegh, 2010).

\subsubsection{Omnidirectional hot-sphere anemometer}

At low velocities, the one-dimensional hot-sphere anemometer is sensitive to the flow direction; an omnidirectional hot sphere anemometer is often preferred for the measurement of the room air movement. An omnidirectional hot sphere anemometer can accurately measure low air velocities, with a limited time response of approximately $20 \mathrm{HZ}$ (Sandberg et al., 2008). The anemometer has two sensors, for the temperature and velocity. The sensors are glass spheres that have a diameter of approximately $2 \mathrm{~mm}$ to $3 \mathrm{~mm}$ and are covered with a the nickel layer. The anemometer operates based on a constant temperature 
mode to reduce the natural convection from the sensor. A small piece of plastic is placed between the temperature and velocity sensors to control the warming of the temperature sensor by the velocity sensor. Melikove (2007) and Lundström et al. (1990) noted that the measurement error sources are obtained by the natural convection generated by the sensor, standard deviation, directional sensitivity of the velocity sensor, velocity and temperature gradients in the flow. Details of the thermal anemometers have been studied by a number of authors, e.g., Bruun (1995); Fingerson (1994) and Melikove (2007). An omnidirectional hot sphere anemometer was applied to measure the airflow distributions within a building; some of the studies are the following citations (Blomqvist and Sandberg, 1997; Karimipanah et al., 2007; Wigö and Sandberg, 2002).

\subsubsection{Temperature measurement}

One of the most common techniques used for temperature sensing in an indoor climate is the thermocouple type- $\mathrm{T}$ (copper-constantan) technique. This sensor is created when two dissimilar metal conductors are joined. At the junction, a small voltage is produced that is a function of the temperature, which converts the thermal energy into the electrical energy. The thermocouple can easily connect to a data logger and computer. The $0.2-\mathrm{mm}$ to $0.5-\mathrm{mm}$ diameter of the sensor is used for indoor climate measurements. In most environment and ventilation temperature measurements, sources of error can arise between the radiation heat exchange between the surrounding surfaces and the sensor (Sandberg et al., 2008). This type of thermocouple was used to measure the surface temperature, air temperature, and inlet and outlet temperature in different studies such as in Törnström (2003).

The thermistor is made of a semi-conduction material and is based on the same principle as a resistance thermometer (Awbi, 2003). A thermistor can be made to be very small, approximately $0.1 \mathrm{~mm}$ in diameter, with a low cost and high resolution.

\subsubsection{Thermal comfort measurement}

The thermal comfort measuring system measures the combined effect of the air velocity, air temperature, operative temperature and humidity 
while considering values for the activity and clothing. A number of such instruments that measure the PMV value have been developed and are described by McIntyre (1980) and ASHRAE (2009c). The system includes different transducers, a thermal comfort data logger and the thermal comfort manager software. The transducers are connected to a data logger, which enables the calculation of PMV and PPD. Thermal comfort software is used to select data from the database and export the PMV and PPD to a Microsoft Excel file. An ellipsoidal comfort transducer is designed to simulate the heat exchange of a human body, which is typically $165 \mathrm{~mm}$ in length and $55 \mathrm{~mm}$ in diameter. To simulate a standing person, the operative temperature transducer has a vertical orientation, and to simulate a seated person, the transducer is tilted at $30^{\circ}$ from the vertical axis. This technique was applied to measure the thermal comfort indexes in different building environments such as offices and a large environmental chamber (Lin, 2011; Pan et al., 2005).

\subsection{Computational Fluid Dynamics (CFD)}

The numerical models in CFD can predict the room airflow, temperature and contaminant distribution in many industrial applications and the internal and external environments of buildings. CFD are user friendly and attractive in terms of the time and cost, and it is of special interest because of the increase in the speed of supercomputers, which have been available for the past three decades. CFD has benefit in performing parametric studies with lower cost for cases in which it is difficult perform measurements. CFD code solves the continuity equation, Navier-Stokes equations, and energy and concentration equations. The finite volume and finite element methods are two main numerical techniques for solving Navies-Stokes equations. CFD provides detailed information in the results and in addition, enables visualization and presentation of the calculated result.

An early CFD model prediction of the room air movement in a ventilated room was given in 1974 (Nielsen, 1974). Some review articles on CFD applications in indoor environments and introductions to the most popular CFD models are the cites provided in the following references: (Awbi, 1998; Chen, 2009; Chen and Zhai, 2004; Jones and Whittle, 1992; Ladeinde and Nearon, 1997; Nielsen, 1975, 1998; Zhai, 2006; Zhai et al., 2007; Zhang et al., 2007) 
Freitas (2002) listed ten important aspects of numerical uncertainties in CFD simulations, some of the items are addressed in this chapter and can be used to evaluate a simulation. In turbulence models, the numerical scheme and the boundary conditions are important factors that affect the simulation accuracy.

In this thesis, the CFD technique, which is a cost-effective tool, is employed to predict the air distribution that issues from the wall confluent jets supply devices into the room, and the numerical results are then compared with the detailed experimental data. Thermal comfort indices and the mean age of the air are predicted via a user-defined function (UDF) that is based on the solved flow and temperature field.

\subsubsection{Turbulence}

Room air flow is a complex flow and is turbulent. Turbulence is a three-dimensional phenomenon, that is characterized by being randomly chaotic and irregular and continually varying in time and space. Instabilities in a flow induce turbulence and generate eddies. Turbulent flows are diffusive and dissipative; they are diffusive because they have a high rate of mixing momentum and heat transfer, and they are dissipative as viscous force transfers kinetic energy into heat. Energy is transferred to the small eddies from the large eddies and so on through a process known as an energy cascade.

\subsubsection{Governing equations}

The airflow and heat transfer are described mathematically by differential equations, which are known as continuity, momentum (Navier-Stokes equations) and energy. The velocity of the turbulent flows can be described as the sum of a mean component and a time-varying fluctuation component that has a zero mean value. This construct is known as Reynolds decomposition, and the resulting time-average Navier Stokes equations are called the Reynolds-Average Navier-Stokes (RANS) equations.

In this study, the flow was assumed to be that of a three-dimensional, steady state, incompressible ideal gas. The buoyancy effect was included in the momentum equation. The Discrete Ordinate radiation heat transfer model was used to account for a radiation model that was recommended 
by (Nielsen et al., 2007). Based on the above assumptions, the equations of continuity, momentum and energy of a Newtonian fluid can be written in a time-averaged form, as follows:

$$
\begin{aligned}
& \frac{\partial U_{i}}{\partial x_{i}}=0 \\
& \frac{\partial\left(U_{j} U_{i}\right)}{\partial x_{j}}=-\frac{1}{\rho} \frac{\partial P}{\partial x_{i}}+v \frac{\partial}{\partial x_{j}}\left(\frac{\partial U_{i}}{\partial x_{j}}+\frac{\partial U_{j}}{\partial x_{i}}\right)+\frac{\partial}{\partial x_{j}}\left(-\overline{u_{\imath}^{\prime} u_{j}^{\prime}}\right) \\
& +g_{i} \beta\left(\Theta-\Theta_{0}\right) \\
& \frac{\partial\left(U_{j} \Theta\right)}{\partial x_{j}}=\frac{\partial}{\partial x_{j}}\left(\alpha \frac{\partial \Theta}{\partial x_{j}}\right)+\frac{\partial}{\partial x_{j}}\left(-\overline{u_{l}^{\prime} \theta^{\prime}}\right)
\end{aligned}
$$

where $\overline{u_{\imath}{ }^{\prime} u_{\jmath}{ }^{\prime}}$ and $\overline{u_{\imath}^{\prime} \theta^{\prime}}$ are Reynolds stresses and turbulent heat fluxes, respectively. These two terms must be modeled to close the equation system.

\subsubsection{Computational approaches}

Direct numerical simulation (DNS), large eddy simulation (LES) and Reynolds-average Navier-Stokes (RANS) equations are three approaches for the prediction of turbulent flows. DNS solves the whole range of the turbulence scale, such as the Kolmogorov scales and the characteristic length scale. The Kolmogorov scales can be defined in terms of energy dissipation rate and viscosity of the fluid. To capture the smallest eddies in the turbulent flow, a very fine grid resolution is required. DNS also requires very small time step (Versteeg and Malalasekera, 2007). A high grid resolution and small time step make the simulation extremely long; as a result for the present time, the application of DNS for simulating the turbulent flow in indoor flows consumes substantial time and cost. In LES, the large eddies are solved and the small eddies are modeled. The small eddies in LES are less dependent on the geometry; however resolving the large eddies allows having a coarse mesh compared to DNS. LES requires a larger time step than DNS; however, the computational cost with LES in terms of the memory and CPU time is larger than for the RANS models. LES was applied to predict the airflow distribution in an enclosed environment, as in the following studies (Davidson and Nielsen, 1996; Emmerich and McGrattan, 1998; Jiang and Chen, 2001; Musser and McGrattan, 2002). General detail on LES can be 
seen in Sagaut (2002). RANS solves the time-average Navier-Stokes equations by modeling the whole range of the turbulence scales. Therefore, RANS models require far fewer computing resources compared to LES; as a result, most of the numerical studies on ventilation flows for indoor environments have been performed with RANS models. Thus, investigators who are interested in evaluating the air distribution in indoor environments focus on solving the RANS equations.

\subsubsection{RANS models}

RANS turbulence models are divided into Reynolds stress model (RSM) and eddy-viscosity models. The eddy viscosity models can be divided into zero-equation, one-equation, two-equation and multipleequation models, however two-equation models are complete models and are widely used. In eddy-viscosity models, the Reynolds stress terms are modeled by applying Boussinesq's hypothesis (Hinze, 1975), which relates to the mean velocity gradients. According to Boussinesq's hypothesis, the Reynolds stresses can be approximated by:

$-\overline{u_{i}^{\prime} u_{j}^{\prime}}=v_{t}\left(\frac{\partial U_{i}}{\partial x_{j}}+\frac{\partial U_{j}}{\partial x_{i}}\right)+\frac{2}{3} \delta_{i j} k$

where $v_{t}$ is the turbulent viscosity, $k$ is the turbulent kinetic energy, and $\delta_{i j}$ is the Kronecker delta, and the turbulence heat fluxes are modeled as:

$-\overline{u_{\imath} \theta^{\prime}}=-\frac{v_{t}}{\sigma_{t}} \frac{\partial \Theta}{\partial x_{j}}$

where $\sigma_{t}$ is the turbulent Prandtl number and, in this study, is assumed to be constant.

On the other hand, there are more complex RANS models; RSM solves six transport equations of the Reynolds stresses together with the transport equation for the dissipation rate, $\varepsilon$, as well as the heat fluxes; this approach implies that five more transport equations are required to be solved compared with the two-equation eddy-viscosity models. This model also requires much more computer resource compared with the eddy-viscosity models (Chen, 1996).

Two-equation eddy-viscosity models are popular in predicting room air movements that are induced by a ventilation system. Some research 
studies have used two-equation eddy-viscosity models in an enclosed environment, including the following references: (Awbi, 1989; Cho et al., 2008; Karimipanah et al., 2007; Karimipanah and Moshfegh, 2007; Luo and Roux, 2004; Nielsen, 1998; Rohdin and Moshfegh, 2007; Stamou and Katsiris, 2006; Williams et al., 1994a, b; Zhai, 2006). Two-equation eddy-viscosity models were also used successfully for the prediction of flows in the near field of round and multiple round jets (confluent jets) (Ghahremanian and Moshfegh, 2013, 2014a; Ghahremanian and Moshfegh, 2014b; Svensson et al., 2014).

Thus, in this work, three different turbulence models based on twoequation eddy-viscosity models were used to accomplish a numerical prediction of the airflow inside a model room that was ventilated by a WCJ supply device. Each turbulence model has its own pros and cons; the selection of a correct model for the prediction of the air distribution in enclosed environments depends mainly on the accuracy and computing time. Turbulence models, the numerical scheme and the boundary conditions are important factors that affect the simulation accuracy.

The models that were used in this thesis are the renormalization group $k-\varepsilon$, the realizable $k-\varepsilon$ and the shear-stress transport $k-\omega$ model, as described below.

\section{The Renormalization Group (RNG $k-\varepsilon)$ model}

The RNG $k-\varepsilon$ model is derived from the instantaneous NavierStokes equations, using the mathematical technique called the renormalization group method (Yakhot and Orszag, 1986). An additional term in the $\varepsilon$ equation improves the accuracy of the prediction of $k$ in the RNG $k-\varepsilon$ model (Yakhot and Orszag, 1986). The low Reynolds number effects for the flow treatment near the wall regions is included in the RNG $k-\varepsilon$ model. The RNG $k-\varepsilon$ shows the good accuracy for mixing and forced convection when there is a low turbulence level (Zhang et al., 2007).

The turbulence kinetic energy $k$ and its dissipation $\varepsilon$ are given by the following equations: 


$$
\begin{aligned}
\frac{\partial\left(\rho U_{j} k\right)}{\partial x_{j}}=\frac{\partial}{\partial x_{j}} & \left(\left(\mu+\frac{\mu_{t}}{\sigma_{\varepsilon}}\right) \frac{\partial k}{\partial x_{j}}\right)+\mu_{t}\left(\frac{\partial U_{i}}{\partial x_{j}}+\frac{\partial U_{j}}{\partial x_{i}}\right) \frac{\partial U_{i}}{\partial x_{j}} \\
& +\beta g_{i} \frac{\mu_{t}}{\sigma_{t}} \frac{\partial \Theta}{\partial x_{i}}-\rho \varepsilon \\
\frac{\partial\left(\rho U_{j} \varepsilon\right)}{\partial x_{j}}=\frac{\partial}{\partial x_{j}} & \left(\left(\mu+\frac{\mu_{t}}{\sigma_{\varepsilon}}\right) \frac{\partial \varepsilon}{\partial x_{j}}\right) \\
& +C_{1 \varepsilon} \frac{\varepsilon}{k}\left[\mu_{t}\left(\frac{\partial U_{i}}{\partial x_{j}}+\frac{\partial U_{j}}{\partial x_{i}}\right) \frac{\partial U_{i}}{\partial x_{j}}+C_{3 \varepsilon} \beta g_{i} \frac{\mu_{t}}{\sigma_{t}} \frac{\partial \Theta}{\partial x_{i}}\right] \\
& -C_{2 \varepsilon} \rho \frac{\varepsilon^{2}}{k}+\frac{C_{\mu} \eta^{3} \rho(1-\eta / 4.38}{1+0.012 \eta^{3}} \frac{\varepsilon^{2}}{k}
\end{aligned}
$$

where the eddy viscosity $\mu_{t}=C_{\mu} \rho \frac{k^{2}}{\varepsilon}$ and constants are listed below (ANSYS, 2012):

$$
C_{1 \varepsilon}=1.42, \quad C_{2 \varepsilon}=1.68, \quad C_{\mu}=0.0845, \quad \eta=S \mathrm{k} / \varepsilon,
$$

$S_{i j}=0.5\left(\frac{\partial U_{i}}{\partial x_{j}}+\frac{\partial U_{j}}{\partial x_{i}}\right), \quad \alpha_{k}=\alpha_{\varepsilon}=1.393, \quad \sigma_{t}=0.85, \quad C_{3 \varepsilon}=\tanh \left|\frac{v_{p a r}}{u_{p e r}}\right|$

( $v_{\text {par }}$ component of velocity parallel to the gravitational vector, $u_{p e r}$ component of velocity perpendicular to the gravitational vector)

\section{The Realizable $(\operatorname{Re} k-\varepsilon)$ model}

The Re $k-\varepsilon$ model was developed by Shih et al. (1995). Realizable means that the model satisfies certain mathematical constraints on the Reynolds stresses (ANSYS, 2012). The model included two important developments: a new formula for the eddy viscosity and a transport equation for modeling $\varepsilon$ (Shih et al., 1995). In the model, $C_{\mu}$ is no longer constant (ANSYS, 2012). The normal Reynolds stresses become positive by applying the new formulation of $C_{\mu}$. The turbulence kinetic energy $k$ is the same as that in the RNG $k-\varepsilon$ model, i.e., Equation 15, while the dissipation $\varepsilon$ is defined as

$$
\begin{aligned}
\frac{\partial\left(\rho U_{j} \varepsilon\right)}{\partial x_{j}}=\frac{\partial}{\partial x_{j}} & \left(\left(\mu+\frac{\mu_{t}}{\sigma_{\varepsilon}}\right) \frac{\partial \varepsilon}{\partial x_{j}}\right)+\rho C_{1} S \varepsilon-\rho C_{2} \frac{\varepsilon^{2}}{k+\sqrt{v \varepsilon}} \\
& +C_{1 \varepsilon} \frac{\varepsilon}{k} C_{3 \varepsilon}\left(\beta g_{i} \frac{\mu_{t}}{\sigma_{t}} \frac{\partial \Theta}{\partial x_{i}}\right)
\end{aligned}
$$

where constants are ANSYS (2012): 


$$
C_{1}=\max \left[0.43, \frac{\eta}{\eta+5}\right], C_{2}=1.9, C_{1 \varepsilon}=1.44, \quad \eta=S \frac{k}{\varepsilon}, \quad S \equiv \sqrt{2 S_{i j} S_{i j}}
$$
, $\sigma_{k}=1.0, \sigma_{\varepsilon}=1.2, \sigma_{t}=0.85, C_{\mu}$ can be seen in ANSYS (2012).

\section{The Shear-Stress Transport (SST $k-\omega)$}

The SST $k-\omega$ model is formulated based on the standard $k-\omega$ and the $k-\varepsilon$ model, which was proposed by Menter (1994). The $k-\varepsilon$ model and standard $k-\omega$ are multiplied by a blending function, which combines them with one another. The blending functions are designed in such a way that they tend to be one in the near-wall region (which activates the standard $k-\omega$ model in the near boundary region) and tend to become zero away from the surface, which activates the $k-\varepsilon$ model (in the outer region). Therefore, the second modification accounts for the transport of the turbulent shear stress.

The transport equation of $k$ and $\omega$ are described below:

$$
\begin{gathered}
\frac{\partial\left(\rho U_{j} k\right)}{\partial x_{j}}=\frac{\partial}{\partial x_{j}}\left(\left(\mu+\frac{\mu_{t}}{\sigma_{k}}\right) \frac{\partial k}{\partial x_{j}}\right)+\widetilde{P_{k}}-\rho \beta^{*} k \omega \\
\frac{\partial\left(\rho U_{j} \omega\right)}{\partial x_{j}}=\frac{\partial}{\partial x_{j}}\left(\left(\mu+\frac{\mu_{t}}{\sigma_{\omega}}\right) \frac{\partial \omega}{\partial x_{j}}\right)+P_{\omega}-\rho \beta \omega^{2} \\
+2\left(1-F_{1}\right) \rho \sigma_{\omega 2} \frac{1}{\omega} \frac{\partial k}{\partial x_{j}} \frac{\partial \omega}{\partial x_{j}}
\end{gathered}
$$

where eddy viscosity $\mu_{t}=\frac{\rho k}{\omega} \frac{1}{\max \left[\frac{1}{\alpha^{*}} \frac{S F_{2}}{a_{1} \omega}\right]}, \tilde{P}_{k}=\min \left(P_{k}, 10 \rho \beta^{*} k \omega\right)$,

$$
\begin{gathered}
P_{k}=\mu_{t} S^{2}, P_{\omega}=\frac{\rho \alpha \widetilde{P_{k}}}{\mu_{t}}, \beta^{*}=\beta_{\infty}^{*}\left(\frac{4 / 15+(k / 8 v \omega)^{4}}{1+(k / 8 v \omega)^{4}}\right), \\
\alpha=\frac{\left(\frac{0.075}{0.09}-\frac{0.41^{2}}{\sigma_{\omega 1} \sqrt{\beta_{\infty}^{*}}}\right) \mathrm{F}_{1}+\left(1-\mathrm{F}_{1}\right)\left(\frac{0.0828}{\beta_{\infty}^{*}}-\frac{0.41^{2}}{\sigma_{\omega 2} \sqrt{0.09}}\right)}{\alpha^{*}}\left(\frac{1 / 9+k / 2.95 v \omega}{1+k / 2.95 v \omega}\right)
\end{gathered}
$$

$$
\beta=0.075 \mathrm{~F}_{1}+0.0828\left(1-\mathrm{F}_{1}\right)
$$

$F_{1}$ and $F_{2}$ are blending function and are giving by

$$
F_{1}=\tanh \left\{\left\{\min \left[\max \left(\frac{\sqrt{k}}{0.09 \omega y}, \frac{500 v}{y^{2} \omega}\right), \frac{4 \rho k}{\sigma_{\omega, 2} D_{\omega}^{+} y^{2}}\right]\right\}^{4}\right\} \text {, }
$$$$
F_{2}=\tanh \left(\max \left[2 \frac{\sqrt{k}}{0.09 \omega y}, \frac{500 \mu}{\rho y^{2} \omega}\right]\right)
$$ 
where $\quad D_{\omega}^{+}=\max \left[2 \rho \frac{1}{\sigma_{\omega, 2}} \frac{1}{\omega} \frac{\partial k}{\partial x_{j}} \frac{\partial \omega}{\partial x_{j}}, 10^{-10}\right], \quad \sigma_{k}=\frac{1}{\mathrm{~F}_{1} / \sigma_{k, 1}+\frac{\left(1-\mathrm{F}_{1}\right)}{\sigma_{k, 2}}}$, $\sigma_{\omega}=\frac{1}{\mathrm{~F}_{1} / \sigma_{\omega, 1}+\frac{\left(1-\mathrm{F}_{1}\right)}{\sigma_{\omega, 2}}}$ and constant are (ANSYS, 2012): $\alpha^{*}=1$, $\sigma_{k 1}=1.176, \quad \sigma_{\omega 1}=2.0, \quad \sigma_{k 2}=1.0, \quad \sigma_{\omega 2}=1.168, \quad \alpha_{1}=0.31$, $\beta_{\infty}^{*}=0.09$

\subsubsection{Boundary conditions}

To obtain a solution for the continuity, momentum and energy equations, the values of the physical parameters (e.g., velocity, temperature and turbulence properties) must be specified on the boundary of the physical model. Typical boundary conditions for an HVAC application are the walls, surfaces, inlet and outlet. In the simulation of a supply device that has complex geometry, a preferred method is to mimic the model with a less complicated geometry that replicates the supply device performance (Chen and Srebric, 2001; Hawkins et al., 1995; Nielsen, 2004). A proper simplification of the supply device configuration can significantly reduce the computational cost. Previous studies by Gosman et al. (1980); Nielsen (1992, 1997); Skovgaard and Nielsen (1991); Srebric and Chen (2002) described different models, such as box, momentum, prescribed velocity, and direct, which are used to specify the inlet boundary conditions for a complex geometry. The box model is an imaginary box that encloses a supply device, for which the physical parameters of the jet are specified from the measured plane. The box model does not require any calculation in the area that is close to the supply device. The flow is ignored within the box and boundary condition is defined by jet profiles at one of the box surfaces, while the other box surfaces use a free boundary that has zero gradients for the flow parameters (Nielsen, 1997). A box size should be small enough to avoid the effect of room dimensions and plumes, and should be larger than the domain with entrainment. Chen and Srebric (2001) recommended the use of a box model for the inlet boundary condition of the nozzle supply device. The box method was chosen for the previous investigations on the wall jet flow that is generated close to the supply device (Nielsen, 1992, 1997). 


\subsubsection{Near wall treatments}

The near-wall region is described in terms of its inner and outer layers. The inner layer can be subdivided into viscous, buffer and fully turbulent layers. In the viscous layer, the flow is almost laminar, and the molecular viscosity is dominant. In the buffer layer (transition zone), the molecular viscosity and the turbulence are equally important. Above the buffer layer is a fully turbulent layer in which turbulence plays a major role. The laminar region is represented by $y^{+}<5$, while the transition and turbulence regions are represented by $5<y^{+}<60$ and $60<y^{+}$(ANSYS, 2012). The dimensionless distance from the wall $y^{+}$is defined as

$y^{+}=y \frac{\rho u_{\tau}}{\mu}$

where $y$ is the distance to the wall, and $u_{\tau}$ is the friction velocity.

The aim was to construct mesh with a $y^{+}$of approximately 1 , while in the $k-\varepsilon$ model, the additional near-wall flows are required to model the innermost layer; then, the enhanced wall treatment was used for the Re $k-\varepsilon$ and RNG $k-\varepsilon$ models in the validation studies.

\subsubsection{Numerical aspects}

The numerical aspects, such as the numerical method, discretization schemes, solving procedure, and convergence criteria, are important to ensure the accuracy of the results. The Finite Volume Method (FVM) is used as the numerical method. In this method, the domain is divided into discrete control volumes. The governing equations are subject to integration over a control volume, and then, we convert the integral equations into algebraic equations to yield discretized equations. An iterative solution is required to solve these nonlinear equations. In this thesis, the finite-volume code ANSYS Fluent uses the SIMPLE pressurevelocity coupling algorithm to determine the pressure field by coupling the pressure and velocity. A second-order upwind scheme is used to improve the accuracy of the prediction (ANSYS, 2012); the second-order scheme is always recommended (Sørensen and Nielsen, 2003). Underrelaxation factors are set to control the updating of the computed variables at each iteration. The number of cells, cell distribution and cell quality affect the solution accuracy, computing time and convergence 
3 Methods

rate. Due to the computational resources, the number of cells cannot be too high; therefore, starting with the coarse mesh and adding cells as necessary in specific regions is always recommended. 


\section{Case studies}

Experimental investigation of air distribution system that was based on conventional wall confluent jets (WCJ) supply device, modified WCJ supply device and impinging confluent jets (ICJ) supply device was performed in an office environment and in industrial premises. The supply devices are described as follows: an array of jets covered by a perforated plate (i.e., conventional WCJ in Paper I), an array of jets on a flat surface (i.e., modified WCJ in Papers II, III, IV, and V), and an array of jets on a curved surface (i.e., ICJ in Paper VI). The modified WCJ supply device was investigated numerically by systematically varying the design of the supply device. Numerical simulations were performed for a comparison of the proposed WCJ supply device with a mixing supply device, displacement supply device and impinging jet supply device. In this chapter, the experimental setup and numerical setup that were conducted for the cases studied are described in detail.

\subsection{Office ventilation}

The measurements were performed in a well-insulated test room, that was located in the Laboratory of Ventilation and Air Quality at the Centre for Built Environment, University of Gävle, Sweden. The room has the dimensions of 4.2 m length, $L$; $3.6 \mathrm{~m}$ width, $W$; and $2.5 \mathrm{~m}$ height, $H$ (Figure 6). This mock-up office environment was furnished with internal heat generation (IHG) (i.e., a personal computer [PC: $115 \mathrm{~W}$ ], a mannequin [95 W], (Mattsson, 1999; Wigö, 2001 ) and four fluorescent lights $[144 \mathrm{~W}])$. To mimic the heat gain via the windows due to solar radiation, the three artificial windows (total window area $2.02 \mathrm{~m}^{2}$ ) and the whole floor were covered by electrically heated foil. Supply device ran the ventilation of the room, which was mounted $1.9 \mathrm{~m}$ above the floor (Figure 6). The exhaust (area $0.062 \mathrm{~m}^{2}$ ) was located at the upper corner of the inlet wall. The differences between the ventilation cooling loads, heat 
loads and heat transmission losses are balanced by the cooling power from a ceiling beam. The Cartesian coordinate system for the test room is sketched in Figure 6. The center of the coordinate system is located in the middle of the inlet wall (or the center of the supply device) $(y=0)$ on its surface $(x=0)$ and $1.9 \mathrm{~m}$ above the floor, $z=0$ (i.e., at the lower part of the conventional WCJ supply device or at the height of the nozzle exit for the modified WCJ). The $z$-axis is oriented toward the floor. The $x$-axis is normal to the inlet wall, and the $y$-axis is parallel to the inlet wall; the positive directions orient toward the windows and exhaust, respectively.
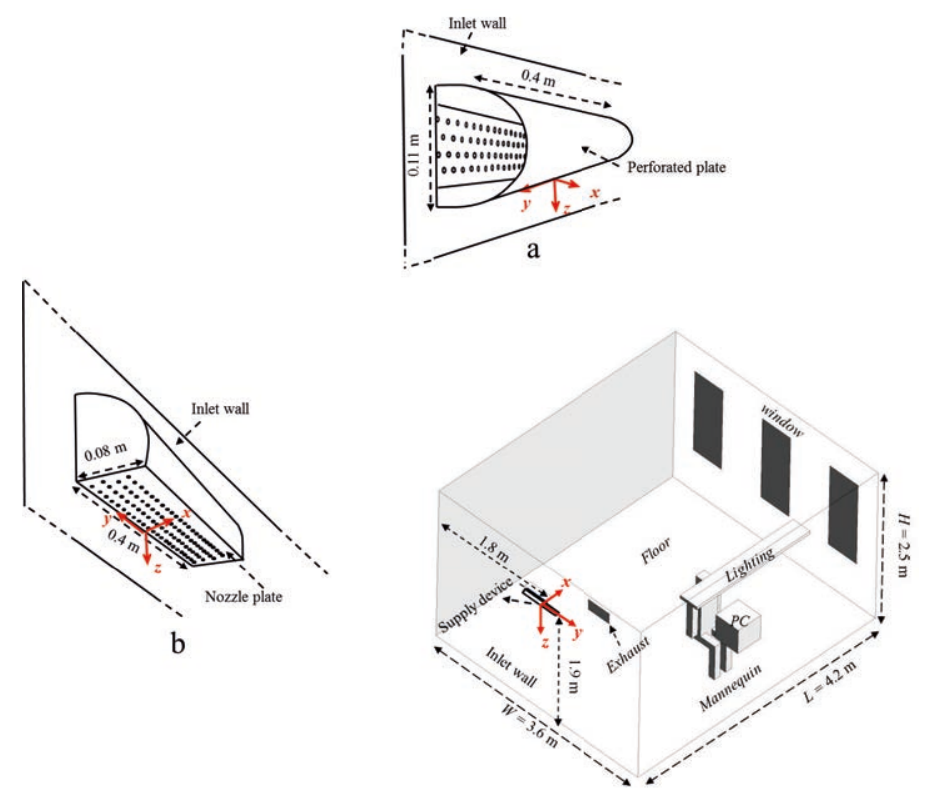

Figure 6. The sketch of the test room with the (a) conventional WCJ supply device and (b) modified WCJ supply device.

\subsubsection{Conventional WCJ supply device}

The performance of a non-isothermal conventional WCJ supply device was investigated experimentally with a focus on the velocity and temperature fields as well as the thermal comfort below the supply device in a test room (Figure 6). The supply air device can be described as 92 round jets that issue from different apertures at the inlet of the supply device, which is covered by an aluminum convex perforated plate (Figure 6a). The supply airflow rate $Q$ varied between $0.02 \mathrm{~m}^{3} / \mathrm{s}$ and 
$0.04 \mathrm{~m}^{3} / \mathrm{s}$, and the difference in temperature between the supply and room mean air was kept at approximately $5-8^{\circ} \mathrm{C}$ (see Paper I, Janbakhsh and Moshfegh (2009)). In this thesis, the case studied had an airflow rate of $0.04 \mathrm{~m}^{3} / \mathrm{s}$, supply temperature of $16^{\circ} \mathrm{C}$, and total heat load of $55 \mathrm{~W} / \mathrm{m}^{2}$ from the PC, mannequin, lighting, floor and windows (the heat loads imposed on the floor and windows were $378 \mathrm{~W}$ and $105 \mathrm{~W}$, respectively).

The temperature distribution below the supply device was visualized by an IR camera (FLIR S60 with accuracy of $\pm 2^{\circ} \mathrm{C}$ ) together with a screen placed parallel to the flow. The one-dimensional HWA (Dantec 55P11) measured the $z$-component of the velocity $w$, and the turbulence intensity $T u$ of the jet along different lines in the $x z$-plane, i.e., the midplane; (see Figure 7) (the internal heat generation is not shown in the figure). The platinum-coated tungsten single-wire probe was $5 \mu \mathrm{m}$ in diameter by $1.25 \mathrm{~mm}$ long. For the calibration of the HWA, low-speed and high-speed open-loop wind tunnel were used. Velocity calibration data were fitted by least-squares regression to a fourth-order polynomial equation. Data acquisition was performed with a National Instrument NI USB-6215. The HWA measured the average air velocity via 18000 samples (sampling rate $100 \mathrm{~Hz}$ ) with an accuracy of $\pm 0.04 \mathrm{~m} / \mathrm{s}$. The different sources of uncertainties were considered to estimate the accuracy of the HWA (i.e., calibration equipment, linearization curve fitting, analog/digital board, temperature variation of sensor, temperature variations in ambient, and ambient pressure). A computer program (Lab VIEW) was applied for automated data gathering. The temperature of the jet along different lines in the vertical mid-plane was logged with a thermistor anemometer (with an accuracy of $\pm 0.1^{\circ} \mathrm{C}$ ) placed on a traversing system. A three-dimensional traversing system (accuracy of $0.0125 \mathrm{~mm}$ ) was used for the automatic movement of the velocity and temperature sensors.

In the various zones inside the room, hot-sphere anemometers (Lundström et al., 1990) were used to measure turbulence intensity and the low-velocity airflow with an accuracy of $5 \% \pm 0.05 \mathrm{~m} / \mathrm{s}$, as recommended by Sandberg et al. (2008). The hot-sphere anemometers were equipped with a bead thermistor instead of a nickel-covered glass sphere. The probes were connected to a multichannel system that was interfaced with a computer. The velocity measurements via probes 
comprised 150 samples at 2-s intervals (Karimipanah et al., 2007). The probes were calibrated within the range $0.05-1.2 \mathrm{~m} / \mathrm{s}$. Measurements were made at four levels: the ankle, waist, and neck heights of a sitting person and the neck height of a standing person (i.e., $z^{*}=0.1,0.6,1.1$, and $1.7 \mathrm{~m}$ from the floor) for various zones.

The vertical temperature gradient was measured in the various zones with hot-sphere anemometers that had an accuracy of $\pm 0.2^{\circ} \mathrm{C}$. In addition, eighty type-T (copper-constantan) thermocouples with an accuracy of $\pm 0.1^{\circ} \mathrm{C}$ were used to measure the room surface temperatures (walls, floor, and ceiling), inlet, and exhaust as well as the air temperature gradient. The thermocouples were connected to a computer-controlled data acquisition device (Agilent 34970). All of the thermocouples were covered with adhesive tape (a similar color and emissivity as the measured surface) on the surfaces of the walls for the elimination of radiation effects (Cehlin et al., 2002).

The INNOVA transducers were used to measure the air velocity, air temperature, operative temperature, and humidity to calculate the PMVs and PPDs according to ISO 7730 (2005). The air velocity was logged via a transducer (accuracy $\pm 0.05 \mathrm{~m} / \mathrm{s}$ ), based on the constant temperature difference anemometer principle. Temperature transducers recorded the air temperature and operative temperature with an accuracy of $\pm 0.2^{\circ} \mathrm{C}$ and $\pm 0.3^{\circ} \mathrm{C}$, respectively. The comfort level was set at the metabolic rate of 1.2 met and the clothing at 0.7 clo, as in ISO 7730 (2005).

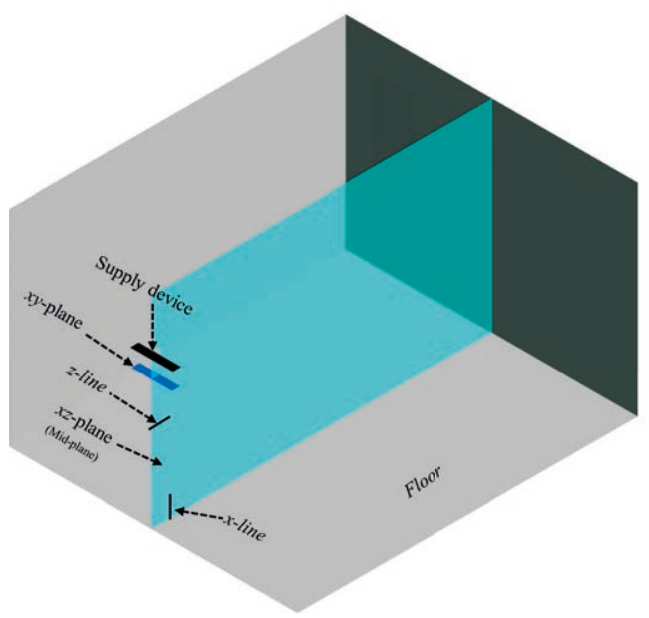

Figure 7. Example of measurement planes and lines 


\subsubsection{Modified WCJ supply device}

The characteristics of the flow field and ventilation performance of the modified WCJ supply device in terms of the thermal comfort and ventilation effectiveness were investigated experimentally and numerically inside the room (Papers II, III, IV).

A total of six experimental cases were used to investigate the isothermal and non-isothermal flow from a modified WCJ supply device in the test room (Paper II, Janbakhsh and Moshfegh (2014a)). In the experimental study, air issues from a staggered array of jets on a flat surface, which are placed at $z^{*}=1.9 \mathrm{~m}$ above the floor. Each nozzle has a diameter $d$ of $5.6 \mathrm{~mm}$, and the spacing (nozzle centers) is $17 \mathrm{~mm}$ for two nozzles on the same row. First, two isothermal cases with different airflow rates, $Q=0.015$ and $0.0195 \mathrm{~m}^{3} / \mathrm{s}$, were measured for more detailed analysis. Second, three non-isothermal cases were examined with $Q=0.015,0.0195$, and $0.025 \mathrm{~m}^{3} / \mathrm{s}$; an air supply temperature of approximately $16{ }^{\circ} \mathrm{C}$; and a total heat load of $40 \mathrm{~W} / \mathrm{m}^{2}$ inside the room, which was generated by IHG (as mentioned in section 4.1), floor (150 W) and windows $(105 \mathrm{~W})$. One more non-isothermal case was also examined that had an airflow rate of $0.0195 \mathrm{~m}^{3} / \mathrm{s}$, supply temperature of $16^{\circ} \mathrm{C}$, and total heat load of $55 \mathrm{~W} / \mathrm{m}^{2}$, in which the heat imposed on the floor was $378 \mathrm{~W}$. The cases studied for the modified WCJ supply device are presented in this thesis for the airflow rates of 0.015 and $0.025 \mathrm{~m}^{3} / \mathrm{s}$.

The same measurement instruments were used as mentioned above in section 4.1.1. The visualization of the flow and temperature distribution of a modified WCJ supply device were accomplished by smoke and an infrared camera. Below the supply device, a constant temperature HWA and a thermistor were placed on a three-dimensional traversing system to capture the temperature, $z$-component velocity $w$, and turbulence intensity $T u$ profiles at various lines in the $x y$ - and $x z$ - planes. Examples of measurement planes and lines are shown in Figure 7 . The hot-sphere anemometer recorded the air temperature and air velocity at four heights $\left(z^{*}=0.1,0.6,1.1\right.$, and $\left.1.7 \mathrm{~m}\right)$ in various zones. The thermal comfort transducers recorded the PMVs and PPDs at four heights in the middle of the room. The details of the measurement lines with the number of point measurements in each line can be seen in appended Paper II. In addition, the experimental results were evaluated by repeating certain measurements. 
The RNG $k-\varepsilon$, Re $k-\varepsilon$, and SST $k-\omega$ models were used to predict numerically the velocity and temperature of the flow of an isothermal and non-isothermal modified WCJ supply device (Papers III and IV; Janbakhsh and Moshfegh (2014b) and Janbakhsh and Moshfegh (2015)). The models were validated with detailed experimental measurements for isothermal cases in which the box model of geometry $(x=0.10 \mathrm{~m}, y=0.53 \mathrm{~m}, z=0.09 \mathrm{~m})$ was used for the inlet boundary condition, i.e., the Computational Box (CB) (Paper III). To further investigate the dependency of the modified WCJ supply device on the inlet airflow rate, three cases $\left(Q=0.015,0.0175\right.$, and $\left.0.0195 \mathrm{~m}^{3} / \mathrm{s}\right)$ with an inlet position at $z^{*}=1.8 \mathrm{~m}$ were examined. The impact of the inlet discharge height $\left(z^{*}=2.01,1.81\right.$, and $\left.1.61 \mathrm{~m}\right)$ was also investigated with an identical airflow rate $\left(Q=0.015 \mathrm{~m}^{3} / \mathrm{s}\right)$. The cases were simulated by the RNG $k-\varepsilon$ model, although all three turbulence models were found to produce good simulation results when compared with the measurements. In the non-isothermal cases, the validation cases $(Q=$ $0.015,0.0195$, and $0.025 \mathrm{~m}^{3} / \mathrm{s}$ with a total heat load of $40 \mathrm{~W} / \mathrm{m}^{2}$ ) based on the CB and Nozzle Plate (NP) models numerically predict and compare the velocity and temperature results with measured data (Paper IV). The CB and NP models were used to model the inlet boundary conditions of a modified WCJ supply device. The same size box as mentioned in the isothermal cases was used in the non-isothermal cases. In the NP model, the supply device was modeled by air issuing from round jets, and these jets had the same staggered array, number of nozzles, nozzle diameter, and spacing between nozzles as those of the experimental cases.

In the parametric study (Table 1) for the non-isothermal cases, the impact of the nozzle array configuration $r \times c$, nozzle diameter, number of nozzles, and inlet discharge height from the modified WCJ supply device of varying design were examined for their ventilation performance in terms of the thermal comfort and ventilation efficiency (heat removal effectiveness) (Paper IV). The variables $r$ and $c$ denote the number of rows and columns, respectively. Fifteen cases (termed 1-15) of this parametric study were simulated numerically using the SST $k-\omega$ (NP) turbulence model, supply airflow rate of $0.025 \mathrm{~m}^{3} / \mathrm{s}$, supply temperature of $16^{\circ} \mathrm{C}$, and total heat load of $17 \mathrm{~W} / \mathrm{m}^{2}$ from IHG in the room. According to Table 1, the nozzles of the array have an in-line configuration (except for case 1), with the nozzle centers spaced by 14 mm (except for cases 1, 2 and 3). The first two cases (1 and 2) had 
identical nozzle diameters and the same number of nozzles and were compared to show that the flow behavior is independent of the nozzle configuration (i.e., staggered or in-line nozzle arrays) (see Paper IV for more details).

Table 1. Configuration of the modified WCJ supply device for parametric studies.

\begin{tabular}{cccc}
\hline Case & $\begin{array}{c}\text { Nozzle array } \\
\text { configuration } r \times c\end{array}$ & $\begin{array}{c}\text { Nozzle diameter } \\
(\mathrm{mm})\end{array}$ & $\begin{array}{c}\text { Inlet discharge height } \\
(\mathrm{m})\end{array}$ \\
\hline \hline 1 & $23 \times 4$ st & 5.6 & 1.9 \\
2 & $23 \times 4$ & 5.6 & 1.9 \\
3 & $24 \times 4$ & 5.6 & 1.9 \\
4 & $12 \times 8$ & 8 & 1.9 \\
5 & $8 \times 12$ & 8 & 1.9 \\
6 & $24 \times 4$ & 8 & 1.9 \\
7 & $24 \times 4$ & 10 & 1.9 \\
8 & $24 \times 6$ & 8 & 1.9 \\
9 & $24 \times 6$ & 10 & 1.9 \\
10 & $24 \times 6$ & 10 & 1.6 \\
11 & $24 \times 6$ & 10 & 1.3 \\
12 & $24 \times 8$ & 8 & 1.9 \\
13 & $24 \times 8$ & 10 & 1.9 \\
14 & $24 \times 8$ & 10 & 1.6 \\
15 & $24 \times 8$ & 10 & 1.3 \\
\hline "r" number & of row, "c & number of column and & "st" staggered \\
configuration & & &
\end{tabular}

Finally, a total of six cases was numerically studied to compare the ventilation performance of the proposed WCJ supply device with a mixing supply device, impinging jet supply device, and displacement supply device. Details of the cases studied can be seen in Paper V (Chen et al., 2015). The proposed WCJ supply device (i.e., case 14 in Table 1, with the moderate installation height) was chosen after the parametric studies, as mentioned above. The ventilation performance in terms of the thermal comfort (i.e., PMV, PPD, and DR), ventilation efficiency ( $\varepsilon_{t}$ and $\varepsilon_{a}$ ), and energy-saving potential were evaluated for the supply devices. In this thesis, the ventilation performance of the supply devices is presented only for a case with the airflow rate of $0.025 \mathrm{~m}^{3} / \mathrm{s}$, supply temperature of $16^{\circ} \mathrm{C}$, and total heat load of $17 \mathrm{w} / \mathrm{m}^{2}$ (from PC, mannequin, and lighting). The energy-saving potential is addressed based on the airflow rate and related fan power that are required for obtaining a similar occupied zone temperature (approximately $24.2^{\circ} \mathrm{C}$ ) for the supply devices. 
In isothermal studies (Paper III), the ANSYS mesh-design modeler (Workbench 13.0) was used to create the model and to generate mesh for the empty room. In non-isothermal validation studies (Paper IV), the room with internal heat sources was constructed and meshed in ICEPAK 4.4.8 (2007). In both papers III and IV, the mesh was generated using three-dimensional structured hexahedral cells. For the model with the nozzle plate (Paper IV and V), AIRPAK 3.0.16 (2007) was used to create the model and generate unstructured hexahedral cells. The non-conformal mesh strategy was adapted around the nozzle plate and heat sources to reduce the total amount of mesh through the whole domain, as recommended in Cehlin and Moshfegh (2010) and Rohdin and Moshfegh (2007). The non-conformal interface was not used for calculating the mean age of the air due to the problems that were encountered using the User-Defined Scalar (UDS) equation. The grid is sufficiently refined near the solid walls to solve all of the boundary layers with the two-layer model. The models were solved with at least three different grids. Details of the mesh strategy can be found in appended Papers III, IV, and V. The mesh configuration that was used for the non-isothermal validation cases is illustrated in Figure 8.
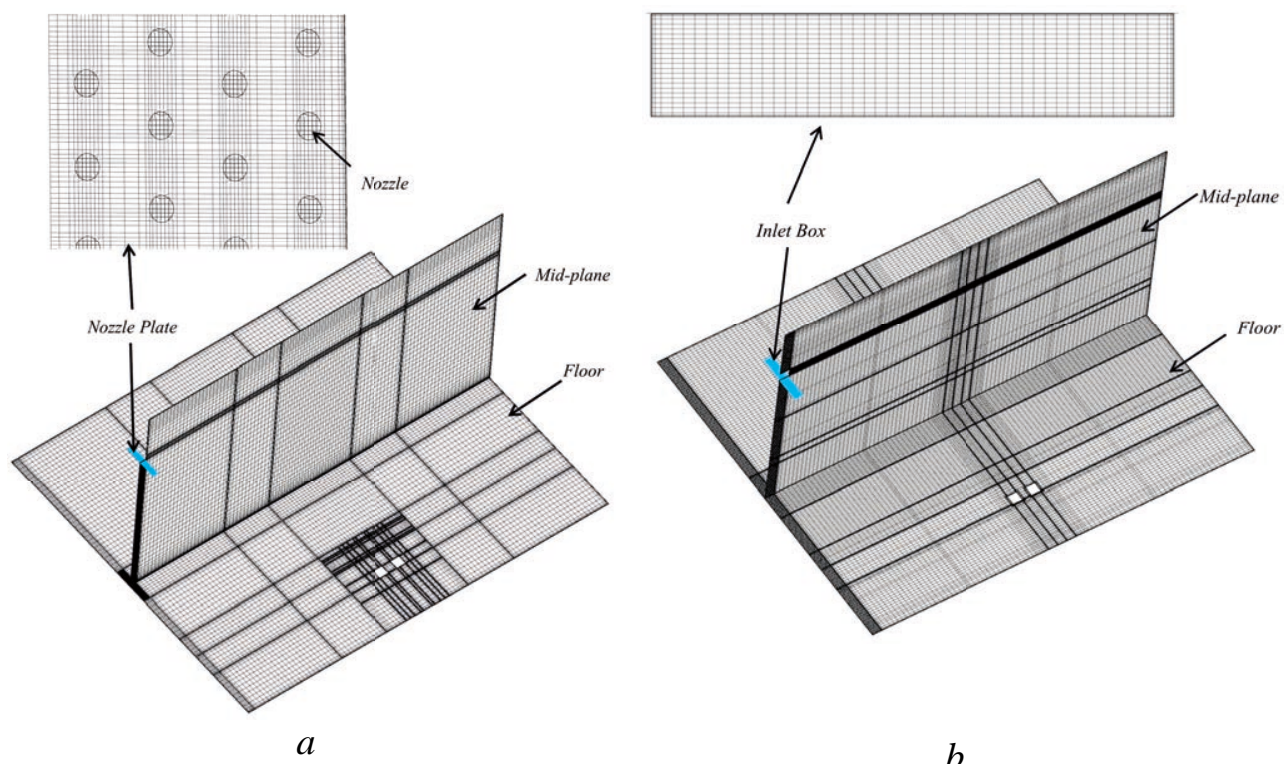

$b$

Figure 8. The computational grid for the mid-plane, floor and inlet of the (a) nozzle plate and (b) computational box (the sources of internal heat generation are not shown) (Paper IV). 
The finite-volume solver ANSYS Fluent 13 and 14.5 (ANSYS, 2010, 2012) was employed to predict the airflow from the modified WCJ supply device. The pressure-velocity coupling was controlled by the SIMPLE algorithm. A second-order upwind scheme was used to improve the accuracy of the predictions. The solutions were considered to have converged when the relative change of any local variable between two consecutive iterations was below $10^{-5}$ for continuity, with velocity components $(u, v, w), k, \omega, \varepsilon$, and below $10^{-8}$ for the energy.

In both Papers III and IV, for the CB model, the velocity component $w$ in the $z$-direction and the temperature measured at plane $x y(z=0.09 \mathrm{~m})$ were provided as the inlet boundary condition in Figure 9. The inlet boundary condition for the turbulent kinetic energy and its dissipation were obtained using the following equations:

$k=1.5(w T u)^{2}$

$\varepsilon=\frac{C_{\mu}^{3 / 4} k^{3 / 2}}{l}$

where $T u$ is the turbulence intensity of the measured $(w), C_{\mu}$ is an empirical constant (0.09), and $l$ is the length scale given by the 0.07 characteristic length of the inlet (ANSYS, 2012; ASHRAE, 2009b). The specific dissipation rate was determined in the $k-\omega$ turbulence model from equation $\omega=\varepsilon / k$. For the NP model (Papers IV and V), a uniform mass flow rate, turbulence intensity, and temperature were provided at the nozzles. The uniform turbulence intensity and hydraulic diameter were used to determine $k, \varepsilon$, and $\omega$. The pressure outlet was chosen for the outlet boundary condition.

The internal and external walls were modeled with no-slip conditions. The average temperatures on each of the internal walls and windows were specified with a uniform value in the validation study (Paper IV), and zero heat flux was set for the internal walls in the parametric study and comparison study (Paper IV and Paper V). Constant heat fluxes were provided for the PC, mannequin, and lighting in the validation and parametric studies (Paper IV). Constant heat fluxes were provided for the PC, mannequin, lighting, floor, window and ceiling in Papers V. The cooling ceiling panel was integrated to supplement the cooling load from the supply devices. 


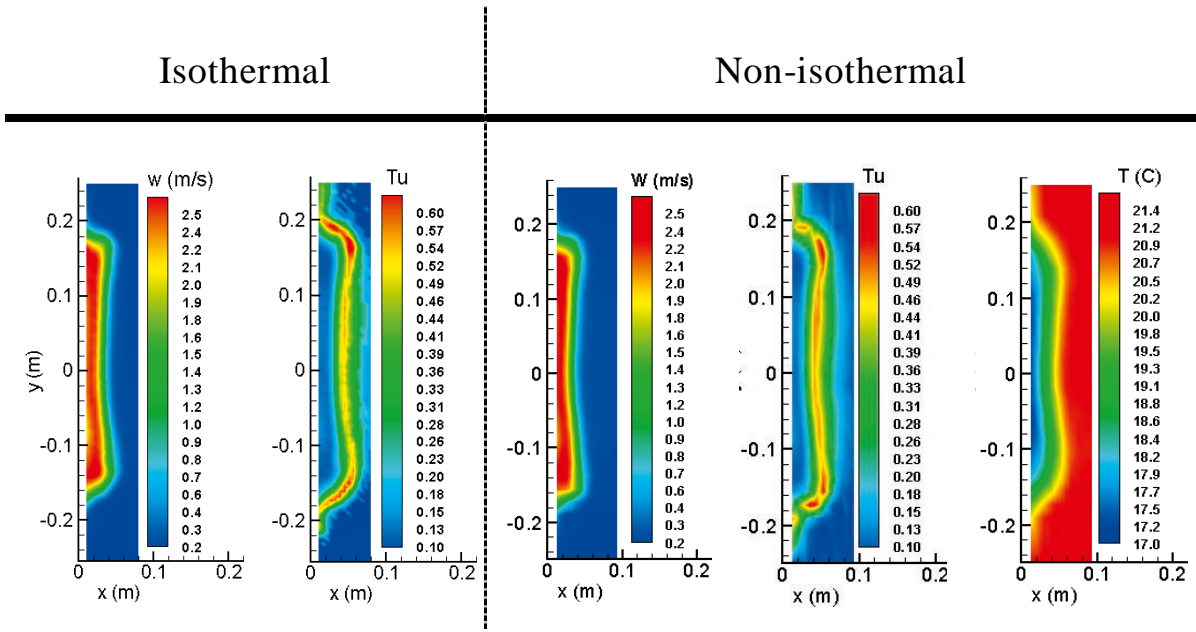

Figure 9. Contour of the measured velocity $w(\mathrm{~m} / \mathrm{s})$ and turbulence intensity $T u$ at $z=0.09$, used for the inlet boundary condition (CB model) for $Q=0.015 \mathrm{~m}^{3} / \mathrm{s}$.

\subsection{Industrial ventilation: ICJ supply device}

An experimental investigation was conducted to evaluate the ventilation performance of the ICJ supply device in industrial premises (Paper VI, Janbakhsh et al. (2010)). The facility is located in Tallinn, Estonia, and has a 4,890 $\mathrm{m}^{2}$ floor area, $81.5 \mathrm{~m}$ long and $60 \mathrm{~m}$ wide, with a maximum height of approximately $7.4 \mathrm{~m}$. Air was supplied through 28 supply devices (Figure 10). From each supply device, the jets issued from an array of round jets that were fitted on the body of a cylinder. The supply device under consideration, named ICJ, consisted of nine parallel columns of 58 round nozzles with diameters of $5.8 \mathrm{~mm}$. The supply devices were located vertically against the target wall (pillar face) and were installed $0.29 \mathrm{~m}$ over the floor. The exhausts were placed on the two long, parallel ducts along the facility and were at two different positions at the same level. No external cooling or heating system was installed in the facility. The total heat load consisted of forty people, different machines and two different types of lamps in the facility. 


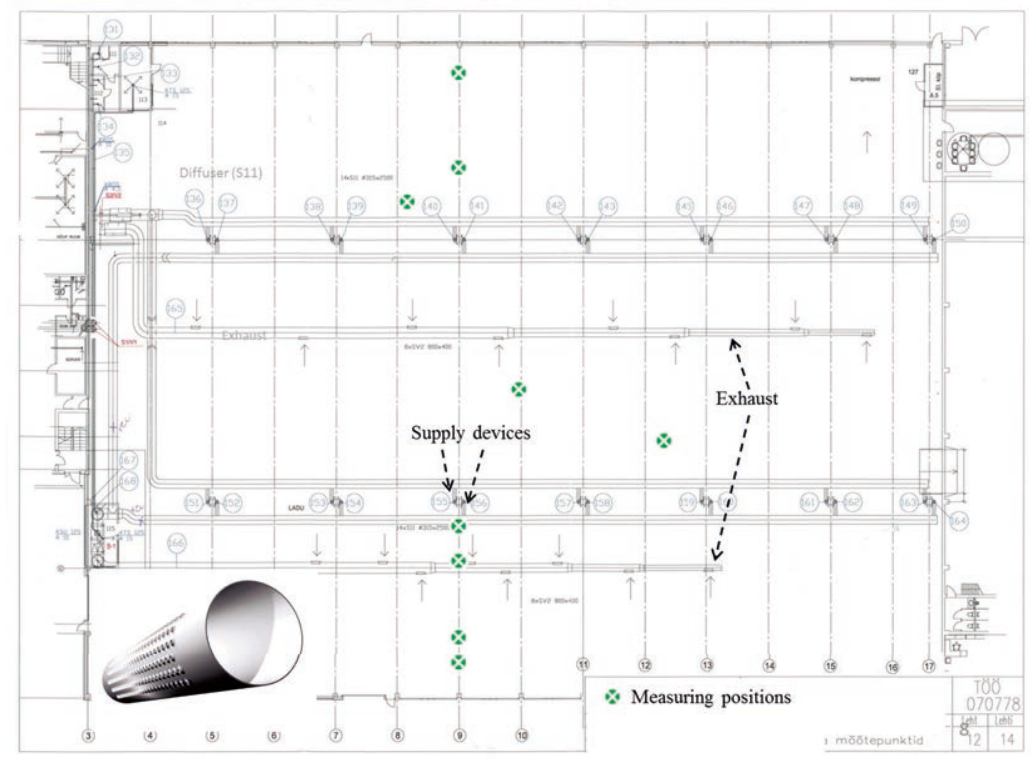

Figure 10. Layout of the facility with the measuring positions and ICJ supply device.

Indoor climate parameters were studied experimentally to quantify the level of thermal comfort and the ventilation strategy of the ICJ supply device in the cooling and heating seasons. Air was supplied through the supply devices, with a total airflow rate of $3.6 \mathrm{~m}^{3} / \mathrm{s}$. The air supply temperature varied between the supply devices from $21.9^{\circ} \mathrm{C}$ to $22.7^{\circ} \mathrm{C}$ and $17.2^{\circ} \mathrm{C}$ to $17.6^{\circ} \mathrm{C}$ for summer and winter, respectively.

In the facility, air velocity measurements were logged close to the supply devices with the hot wire. The probe was connected to the multimeasuring instrument (Testo) for monitoring the data. The probe was $7.5 \mathrm{~mm}$ in diameter. Measurements were performed at different distances and levels from the device and floor to capture the velocity profile in two directions of the flow, and for each point, the velocity was measured for 3 minutes with a sampling rate of $1 \mathrm{~Hz}$ (an accuracy of $\pm 0.03 \mathrm{~m} / \mathrm{s}$ ). The gradient temperature and humidity were measured simultaneously at two positions in the center of the facility. Portable data loggers (Tinytag) recorded the average value of the temperature (accuracy \pm 0.45 ) and humidity (accuracy \pm 0.03 ) every 15 minutes. The INNOVA transducers, which were used for the thermal comfort measurement, were discussed in section 4.1.1. Measurements were performed at heights of 0.1, 0.6, 1.1, 
and $1.7 \mathrm{~m}$ from the floor for various locations. The positions of the thermal comfort measurements are shown in Figure 10. To estimate the thermal comfort of the personnel, measurements were conducted during working hours in the facility. Clothing insulation was set at 0.9 and 0.8 clo for winter and summer, respectively. It should be noted that the medium activity for a standing person of 2 met was applied in both cases. 


\section{Results and discussion}

In this chapter, first the flow behavior and ventilation performance of the conventional WCJ, modified WCJ supply devices and ICJ are investigated experimentally in two different field studies (i.e., test room and industrial premises). Second, numerical predictions of the flow and temperature fields generated by the modified WCJ are evaluated by measurements in an office test room. Third, the ventilation performance in terms of the thermal comfort and ventilation efficiency is numerically investigated by systematically varying the configuration design of the modified WCJ supply device. Finally, the ventilation performance of the proposed WCJ is numerically compared with three different air supply devices in an office environment. Some of the results from this study are presented in this chapter.

\subsection{Experimental study}

\subsubsection{Office ventilation}

The behavior of a ventilated room was studied with the conventional WCJ and modified WCJ supply devices in an experimental test room that represented a typical office environment (Papers I and II).

\subsubsection{Conventional WCJ supply device}

The decay of the non-dimensional maximum velocity $\left(w_{\max } / U_{b}\right)$ is shown in Figure 11a below the supply device, where $U_{b}$ is the bulk velocity (the average velocity of the nozzles). The decay rate of the maximum velocity is slow approximately 0.006 . In Figure $11 \mathrm{~b}$, the nondimensional spreading of the maximum velocity in the normal direction is plotted as a function of the downstream distance in the $z$-direction. The distance from the supply device, $z$, is non-dimensionalized using $A_{n}^{0.5}$, 
where $A_{n}$ is the total area of the nozzles $\left(\mathrm{m}^{2}\right)$. The boundary of the jet becomes wider in the $z$-direction. Figure 11c shows the decay of the minimum temperature difference relative to the room temperature below the supply device, in which $\theta_{\min }=\left(T_{r}-T_{\min }\right) /\left(T_{r}-T_{s}\right)$ is presented as the non-dimensional minimum temperature difference. The minimum temperature difference reduces as the jet decays along the inlet wall.

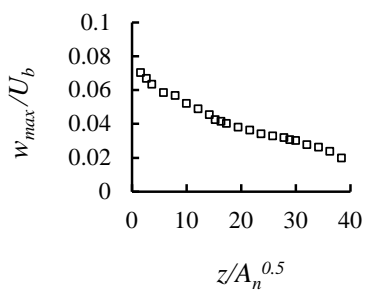

$a$

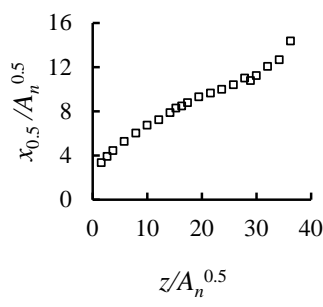

$b$

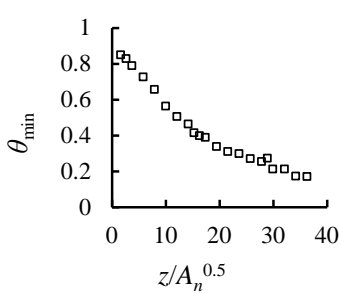

C

Figure 11. Decay of the maximum velocity and minimum temperature difference (a and c); spreading of the jet (b) below the WCJ supply device $\left(Q=0.04 \mathrm{~m}^{3} / \mathrm{s}\right.$, with $\left.T_{s}=16^{\circ} \mathrm{C}\right)$

In the middle of the test room, thermal comfort was assessed by PMV and PPD at an average value of four heights $\left(z^{*}=0.1,0.6,1.1\right.$ and $1.7 \mathrm{~m}$ ); however, DR was calculated at $z^{*}=0.1 \mathrm{~m}$. The value of PMV, PPD and DR for the conventional WCJ supply device were recorded (-0.4), (9\%) and (17\%), respectively. The PMV, PPD, and DR values are at permitted levels that are in accordance with ISO 7730 (2005).

Visualizations of the flow pattern and temperature distribution below the conventional WCJ supply device by the smoke and IR camera are shown in Figure 12. To reduce the entrainment of the room air with the WCJ, the idea of starting to modify the supply device was carried through the investigations on the temperature distribution using the IR camera. The impact of the different configurations of the conventional WCJ supply device were examined in which the perforated plate was fully opened (Figure 12a and b) and was closed from the top and sides (i.e., [c] $90^{\circ}$ open, sides closed, [d] $60^{\circ}$ open from bottom, sides closed, and [e] $30^{\circ}$ open from bottom, sides closed). The temperature distribution using the IR camera shows that the supply device in Figure 12e creates a thinner WCJ than the results in Figure 12b, c and d, which indicates greater entrainment of the room air with its surrounding air for the conventional WCJ supply device in Figure 12b. 


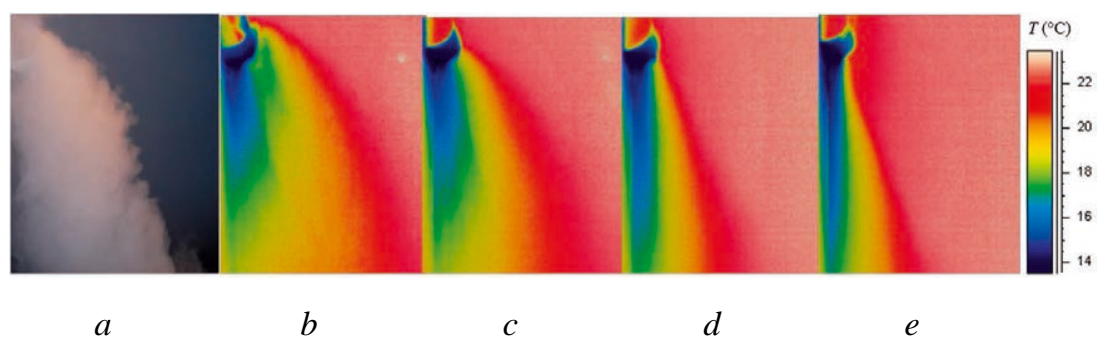

Figure 12. Visualization (side view) of the flow pattern and temperature distribution by smoke (a) and IR camera (b, c, d, and e) of conventional WCJ supply device; (a and b) full open, (c) $90^{\circ}$ open, sides closed, (d) $60^{\circ}$ open from bottom, sides closed, and (e) $30^{\circ}$ open from bottom, sides closed.

\subsubsection{Modified WCJ supply device}

The flow pattern and temperature distribution below the modified WCJ supply device were visualized by the smoke and IR camera, as shown in Figure 13. The visualizations show that the WCJ remains attached to the inlet wall due to the Coanda effect and moves downward.

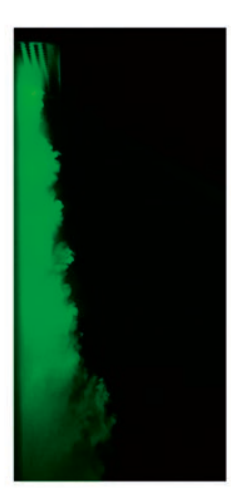

$a$

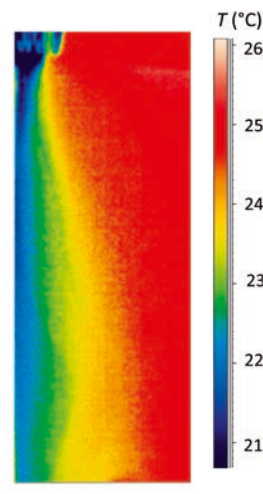

$b$

Figure 13. Visualization (side view) of the flow pattern and temperature distribution by the smoke (a) and IR camera (b) of modified WCJ supply device.

The non-dimensional maximum velocity decay, spreading of the maximum velocity in the normal direction and minimum temperature difference relative to the room temperature are shown in Figure 14 for the modified WCJ supply device. The maximum velocities of the WCJs 
decay linearly, and the rates of the decays are quite similar in the studied range. As shown in Figure 14, the non-dimensional spreading of the maximum velocity in the normal direction increases in the $z$-direction. The decay in the minimum temperature difference is also found to be linear.

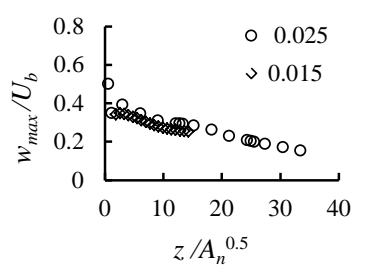

$a$

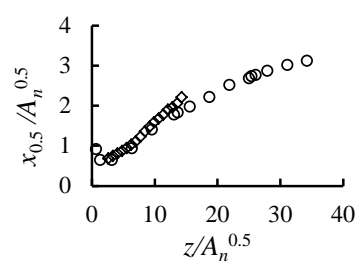

$b$

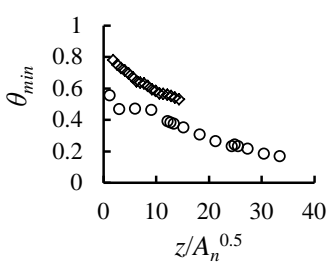

C

Figure 14. Decay of the maximum velocity and minimum temperature difference (a and c); spreading of the velocity (b) below the supply device $\left(Q=0.015\right.$ and $0.025 \mathrm{~m}^{3} / \mathrm{s}$ with $\left.T_{s}=16^{\circ} \mathrm{C}\right)$.

The PMV and PPD are summarized with an average value for four heights at the middle of the room, while the DR is presented for $Z^{*}=0.1 \mathrm{~m}$. The value of PMV, PPD and DR for $Q=0.015 \mathrm{~m}^{3} / \mathrm{s}$ were recorded (-0.6), (12\%) and (20\%), respectively, followed by (-0.7), (17\%) and (30\%) for $Q=0.025 \mathrm{~m}^{3} / \mathrm{s}$. The results show that the modified WCJ supply device operating at a lower airflow rate can provide acceptable thermal comfort for the occupant ISO 7730 (2005), which corresponds to less fan power and saves energy compared to the WCJ supply device. The details of the results can be found in Paper II.

\subsubsection{Industrial ventilation}

Experimental investigations were conducted to study the airflow distribution from the ICJ supply device in industrial premises (Paper VI). Figure 15 shows the profile of the velocity and temperature of the jet as a function of the distance from the floor in the outward direction of the flow, midway between the ICJ supply device and the target wall (i.e., $y=0.06 \mathrm{~m}$ ) and $0.2 \mathrm{~m}$ from the edge of the target wall in the $x$-direction. The results were registered at different vertical heights from the first nozzle at the top to the first nozzle at the bottom of the ICJ. According to Figure 15, the foot-print of the jet has a saddle-back shape, as seen in the study of the modified WCJ (Paper II). The vertical air 
temperature gradient is almost constant due to the dominating region of the issuing jet.

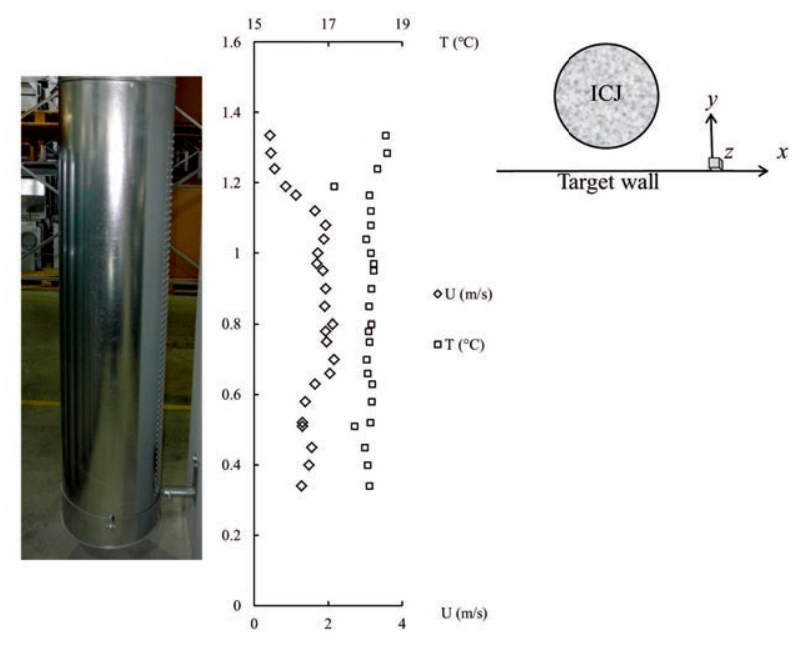

Figure 15. Profile of the velocity $(\mathrm{m} / \mathrm{s})$ from the ICJ supply device.

The average temperature difference between the ankle and neck levels is approximately $0.4^{\circ} \mathrm{C}$ and $0.2^{\circ} \mathrm{C}$ for the winter and summer cases in the facility, respectively. The values for the PMV and PPD were average at the heights of $0.1,0.6,1.1$ and $1.7 \mathrm{~m}$ within the occupied zone in the facility. The PMV and PPD values were 0.8 and $21 \%$ for the summer, followed by 0.3 and $7 \%$ for the winter. The maintained values are acceptable and are in the allowable range according to ISO 7730 (2005). The results of the PPD value become more comfortable for the winter. The average value of DR within the facility is approximately $30 \%$ for both the summer and winter, which is acceptable according to ISO 7730 (2005). Notably, the ICJ supply device provides acceptable thermal comfort in the facility for the winter and summer. The ICJ supply device removes the need for any additional heating and cooling systems during the cold and hot seasons. 


\subsection{Numerical study}

\subsubsection{Validation study}

The WCJ develops a primary region below the supply device with the axis along the inlet wall (z-direction), and a secondary wall jet is formed along the floor ( $x$-direction) after the stagnation region. The flow pattern in the primary and secondary regions can be seen in Figure 16. The jet velocity decay in a non-dimensional form from three turbulence models (RNG $k-\varepsilon$, Re $k-\varepsilon$, and SST $k-\omega$ ) are compared with the measurement (M) data in the primary and secondary regions of the isothermal modified WCJ supply device in Figure 17.

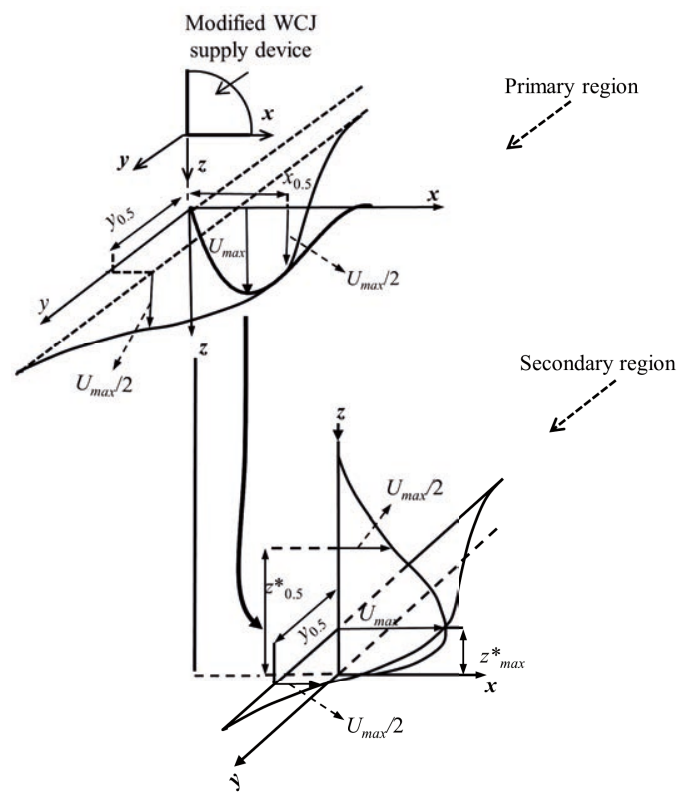

Figure 16. Flow pattern below the modified WCJ supply device in the primary and secondary regions.

As shown in Figure 17, the numerical simulations of the nondimensional maximum velocity with the Computational Box (CB) model are quite similar and agree overall with the measured data for the primary region ( $A$ is the area of the $x y$-plane at $z=0.09\left(\mathrm{~m}^{2}\right)$ ). To further validate the wall jet behavior with numerical predictions by different turbulence models along the floor, the decay of the non-dimensional maximum velocity of the secondary wall jet is depicted in Figure 17. The results 
from the measurement data and numerical predictions are consistent with each other. A comparison of the velocity decays shows that the secondary wall jet tends to decay more slowly than the primary WCJ.

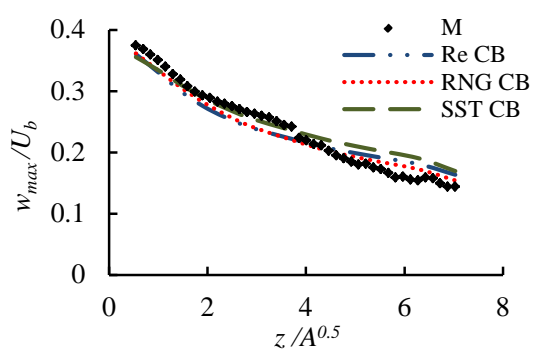

Primary region

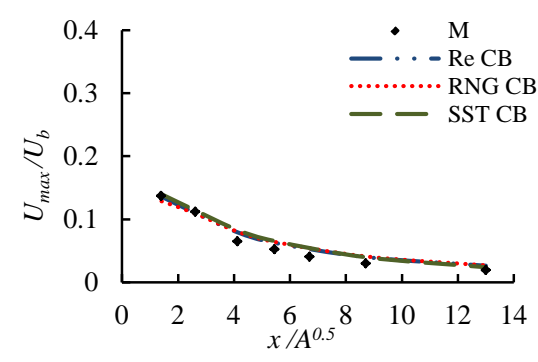

Secondary region

Figure 17. Decay of the maximum velocity in the primary and secondary regions in the mid-plane (isothermal, $Q=0.015 \mathrm{~m}^{3} / \mathrm{s}$ ).

The decays of the non-dimensional maximum velocity and minimum temperature difference relative to the room temperature of three turbulence models (RNG $k-\varepsilon$, Re $k-\varepsilon$, and SST $k-\omega$ ) of the CB model are shown in the primary region for the non-isothermal case in Figure 18. As seen, the results predicted by the turbulence models are in good agreement with the measurement data. However, farther away from the supply device, the SST $k-\omega$ model best predicts the maximum velocity and minimum temperature difference of the WCJ.
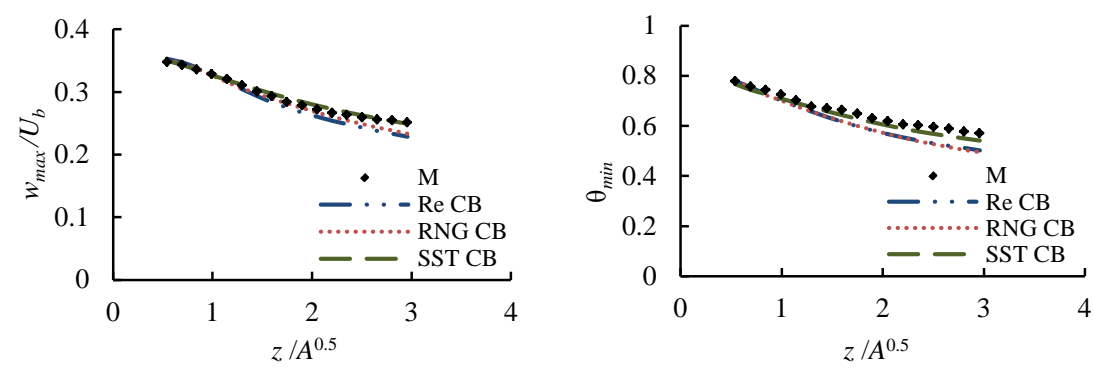

Figure 18. Decay of the maximum velocity and decay of the minimum temperature difference in the primary region in the mid-plane (nonisothermal $Q=0.015 \mathrm{~m}^{3} / \mathrm{s}$ and $T_{\mathrm{s}}=16^{\circ} \mathrm{C}$ ).

Predicted and measured values of the isothermal velocity contour plots in the primary and secondary regions are depicted in Figure 19 for 
$Q=0.015 \mathrm{~m}^{3} / \mathrm{s}$ at the mid-plane. The contour plots of the velocity predicted by the RNG $k-\varepsilon$, Re $k-\varepsilon$, and SST $k-\omega$ models exhibit good consistency in comparison with the measurement result. The contour plots of the velocity field follow a similar pattern for both the measurement and predicted results. No significant difference can be observed between the velocity fields of the three turbulence models. The results predicted by the RNG $k-\varepsilon$ and Re $k-\varepsilon$ models show low velocity and dynamic pressure in the stagnation area of the wall jet, which is not distinguishable from the measurement and SST $k-\omega$ model.

In Figure 19, the WCJ remains attached to the inlet wall due to the Coanda effect and moves downward until reaching to the floor. The thickness of the WCJ grows and becomes wider by entraining ambient air. After the stagnation region, where the jet is attached to its adjacent wall (i.e., floor), the wall jet moves across the floor. The wall jet across the floor is thinner than the WCJ below the supply device, while the latter has stronger momentum than the former.

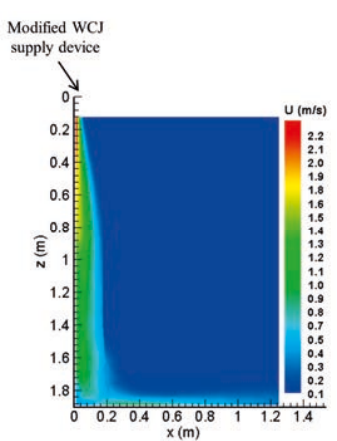

M

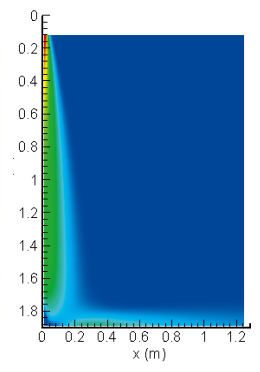

$\mathrm{Re}$

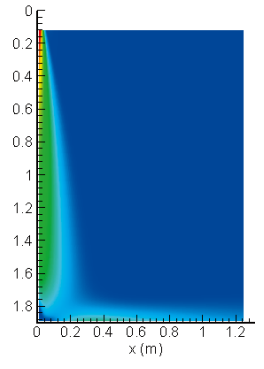

RNG

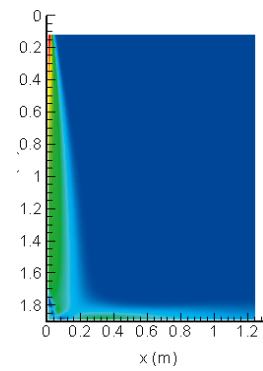

SST

Figure 19. Contour plots of the predicted and measured velocity $(\mathrm{m} / \mathrm{s})$ in the primary and secondary regions at the mid-plane (isothermal, $Q=0.015 \mathrm{~m}^{3} / \mathrm{s}$ ).

Figure 20 shows the contour plots of the numerical predictions of the velocity and temperature by the RNG $k-\varepsilon$, Re $k-\varepsilon$, and SST $k-\omega$ models in comparison with the measurement below the inlet at the midplane. In Figure 20, the cold WCJ remains attached to the inlet wall and moves downward. As the WCJ moves downstream and mixes with the 
surrounding air, the temperature gradient decreases. As shown in Figure 20, the numerical simulations of the CB and NP models exhibit rather similar flow patterns for the velocity and temperature. However, the predicted velocity and temperature fields of the WCJ show a thinner WCJ for the $\operatorname{Re} k-\varepsilon$ (NP) model than that from the RNG $k-\varepsilon$ and SST $k-\omega$ models. A slight discrepancy between the contour plots of the measured and predicted velocity and temperature is observed in the Re $k-\varepsilon$ (NP) model. According to Figure 20, the temperature contour plots of the WCJ predicted by the RNG $k-\varepsilon$ and SST $k-\omega$ models are in agreement with the measured results.

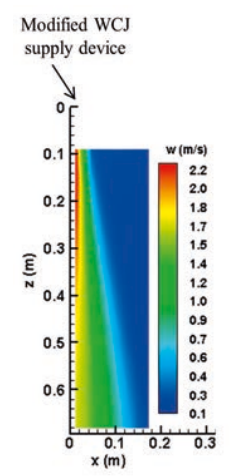

M

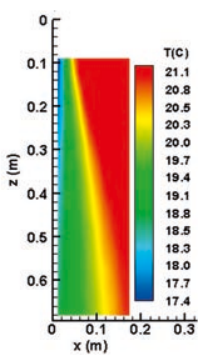

M

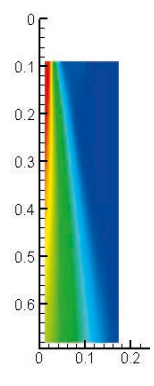

$\operatorname{Re} \mathrm{CB}$

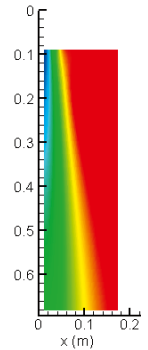

Re CB
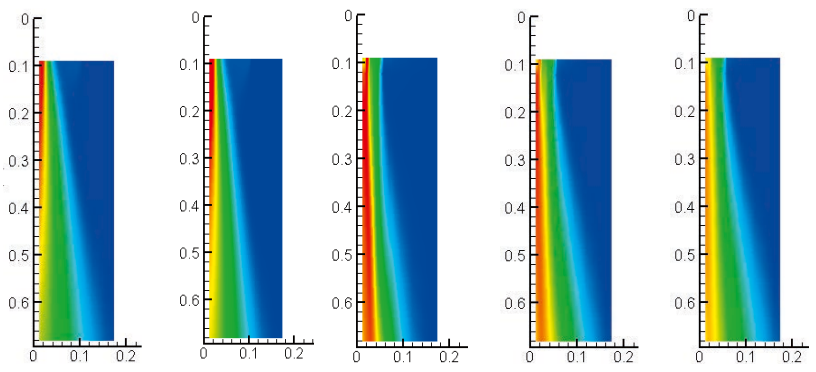

RNG CB

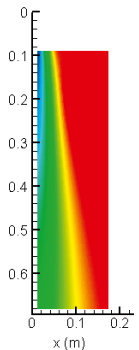

RNG CB

Re NP

RNG NP

SST NP

Figure 20. Contour plots of the predicted and measured air velocity $(\mathrm{m} / \mathrm{s})$ and temperature $\left({ }^{\circ} \mathrm{C}\right)$ in the primary region (non-isothermal $Q=0.015 \mathrm{~m}^{3} / \mathrm{s}$ and $T_{\mathrm{s}}=16^{\circ} \mathrm{C}$ ).

Because the RNG $k-\varepsilon$ and SST $k-\omega$ models predict the velocity and temperature fields better than the Re $k-\varepsilon$ model, the numerical 
predictions of the velocity and temperature profiles by these two models are shown in comparison with the measurement lines below the inlet. The velocity and temperature profiles are shown in Figure 21 from the left for $z=0.33,0.54$, and $0.68 \mathrm{~m}$ at the mid-plane. The numerical simulations of the CB and NP from the RNG $k-\varepsilon$ and SST models are quite similar to each other and are also in good agreement with the measurement data for both the temperature and velocity. The SST $k-\omega$ model predicts the velocity slightly better than the RNG $k-\varepsilon$ model, while the velocity of the WCJ is maximal.
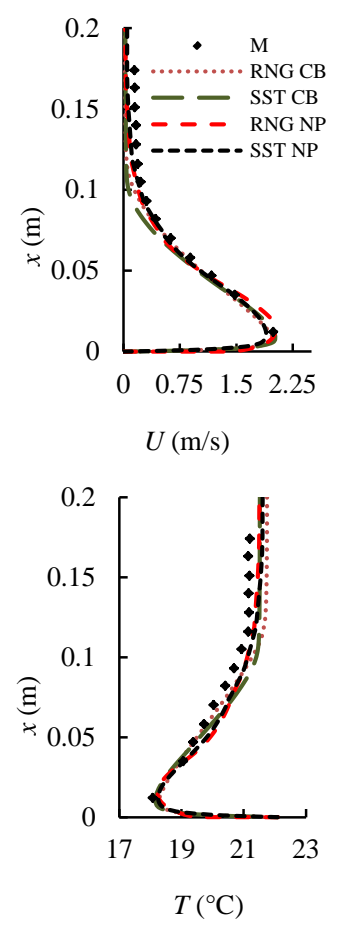
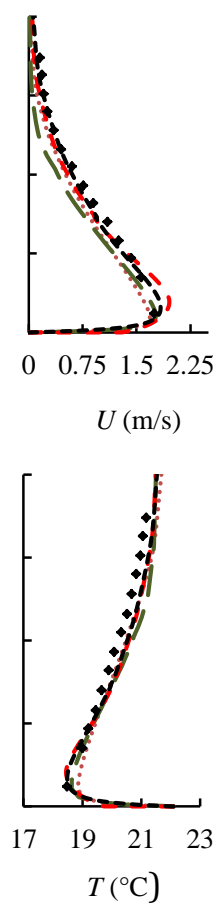
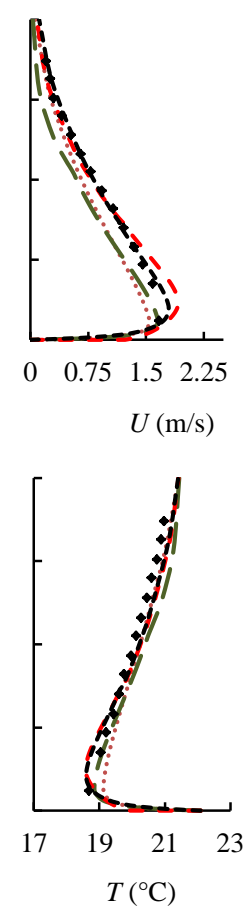

Figure 21. Measured and predicted velocity and temperature profiles in the mid-plane at $z=0.33 \mathrm{~m}$ (left), $0.54 \mathrm{~m}$ (middle), and $0.68 \mathrm{~m}$ (right) ( $Q=0.015 \mathrm{~m}^{3} / \mathrm{s}$ and $\left.T_{\mathrm{s}}=16^{\circ} \mathrm{C}\right)$.

To evaluate the numerical prediction of the flow behavior of the secondary wall jet using the RNG $k-\varepsilon$ and SST $k-\omega$ models, the velocity and temperature profiles are compared for three different locations from the inlet wall along the $z$-direction (from the left $x=0.7$, 2.1, and 3.5) at the mid-plane (see Figure 22). The predicted velocity and 
temperature profiles using the $\mathrm{CB}$ and NP models show agreement with the measured data. As shown in Figure 22, according to the standard criteria from ISO 7730 (2005) and ASHRAE Standard 55 (2004), the velocity is less than $0.2 \mathrm{~m} / \mathrm{s}$, except for close to the floor and at a height of $0.1 \mathrm{~m}$ from the floor, for $x=0.7 \mathrm{~m}$.
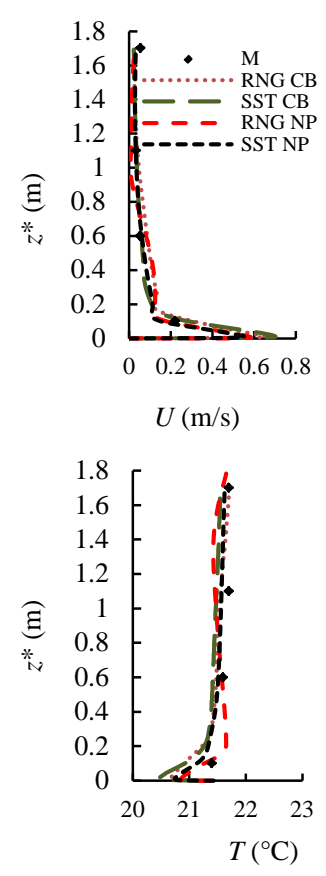
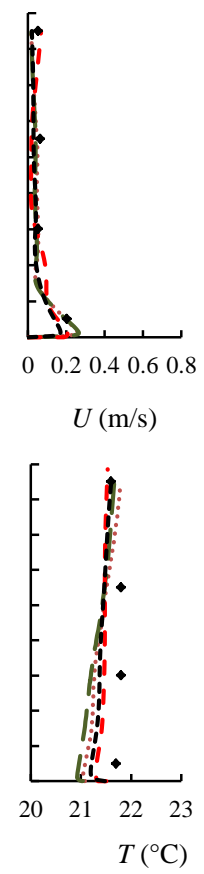
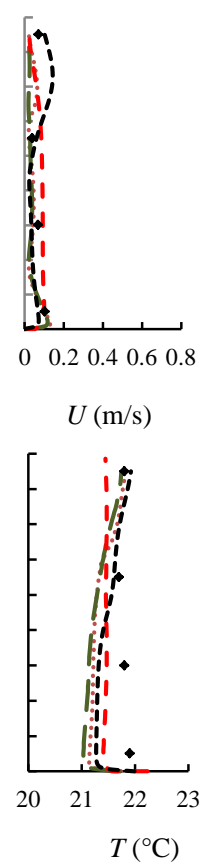

Figure 22. Measured and predicted velocity and temperature profiles in the mid-plane at three distances downstream from the inlet wall, i.e., $x=0.7 \mathrm{~m}$ (left), $2.1 \mathrm{~m}$ (middle), and $3.5 \mathrm{~m}$ (right) $\left(Q=0.015 \mathrm{~m}^{3} / \mathrm{s}\right.$ and $\left.T_{\mathrm{s}}=16^{\circ} \mathrm{C}\right)$.

\subsubsection{Parametric study}

Parameters related to the nozzle diameter, number of nozzles, nozzle array configuration, supply airflow rate, and inlet discharge height were investigated with the use of CFD simulations.

\subsubsection{Isothermal cases}

Under isothermal conditions, the effect of the varying supply airflow rates on the spreading rate and the velocity decay of the wall jet is shown in Figure 23 and are considered in Paper III. The spreading rates of the 
wall jet in the vertical $\left(z^{*}\right)$ and lateral $(y)$ directions across the floor are presented in non-dimensional form as $z_{0.5}^{*} / A^{0.5}$ and $y_{0.5} / A^{0.5}$, respectively. As shown in Figure 23, all of the wall jets have similar behavior along the centerline of the floor and spread at a similar rate; therefore, the flow behavior is almost independent of the studied airflow rates. The spreading rates of the wall jet in the lateral direction reached a plateau for all three airflow rates.

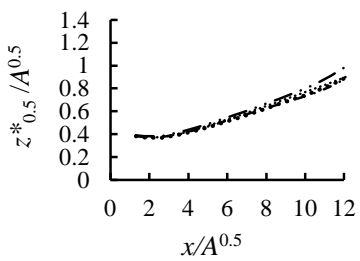

Vertical spreading

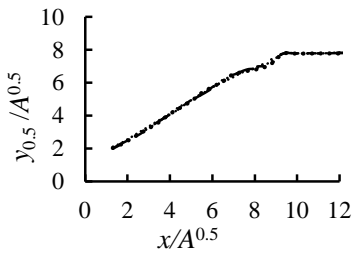

Lateral spreading

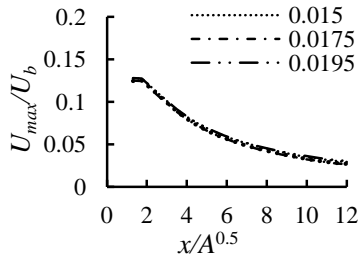

Decay of maximum velocity

Figure 23. Effect of the supply airflow rate on vertical and lateral spreading and the decay of the maximum velocity of the wall jet in the secondary region.

A comparison spreading rate of the wall jet and decay of the maximum velocity for three inlet discharge heights are shown in Figure 24 for the isothermal case, with an identical airflow rate $\left(Q=0.015 \mathrm{~m}^{3} / \mathrm{s}\right)$. According to Figure 24, the graphs follow each other closely, and the decay tendencies appear to be almost similar for three inlet heights. As shown by the lateral spreading rate of the wall jets, all three graphs reach a plateau at $x / A^{0.5} \approx 10$. Notably, close to the inlet wall $\left(x / A^{0.5} \leq 2\right)$, the maximum velocity tends to decay slightly faster for the inlet discharge height of $1.61 \mathrm{~m}$; this effect cannot be seen as the wall jet enters the room.

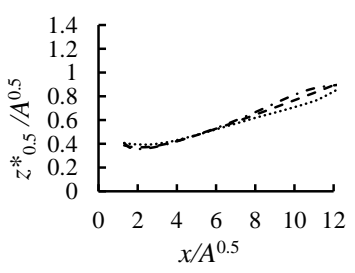

Vertical spreading

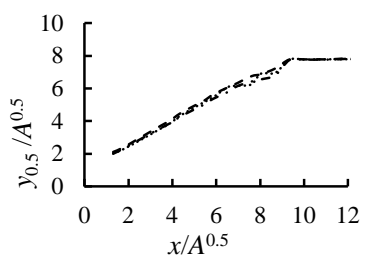

Lateral spreading

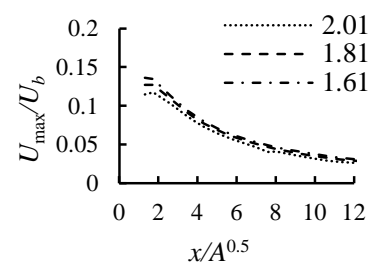

Decay of maximum velocity

Figure 24. Effect of the inlet discharge height on the vertical and lateral spreading and decay of the maximum velocity of the wall jet in the secondary region. 


\subsubsection{Non-isothermal cases}

The impacts of different configurations of modified WCJ supply device on the ventilation performance are examined (see Table 1). In this thesis, two cases are presented, the modified WCJ supply device (case 1) and the proposed WCJ supply device (case 14), of which case 14 covers the important studied parameters. A discussion on the ventilation performance from the other cases that were studied can be found in Paper IV.

As shown in Figure 25, the vertical spreading rates of the wall jets are similar and spread at a similar rate, while the wall jet in the lateral direction reached a plateau slightly earlier in case 1 than in case 14 ( $Q=0.025 \mathrm{~m}^{3} / \mathrm{s}$ and $T_{\mathrm{s}}=16^{\circ} \mathrm{C}$ ). A comparison of the maximum velocity decay shows that the wall jet initially tended to decay faster for case 14 than for case 1 . The results show that the lateral spreading and decay of the maximum velocity depend on to the design parameters. Notably, $A_{n}$ is the total area of the nozzles for each case.

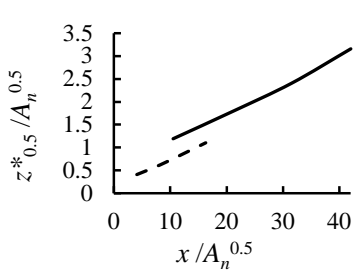

Vertical spreading

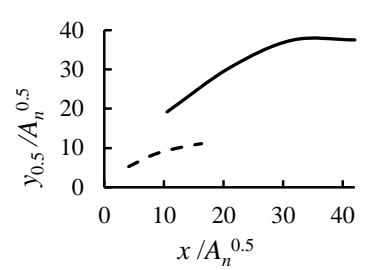

Lateral spreading

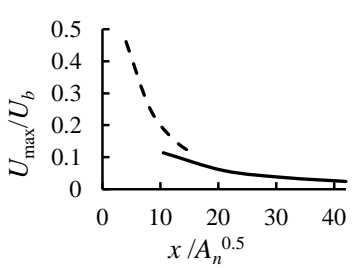

Decay of maximum velocity

Figure 25. Vertical and lateral spreading of the wall jet and decay of the maximum wall jet velocity across the floor for the modified WCJ (case 1, solid line) and proposed WCJ (case 14, dash line).

To explain the difference in the flow pattern that results from varying the design, iso-velocity contour plots at $0.25 \mathrm{~m} / \mathrm{s}$ are depicted in Figure 26a. The flow spreads farther along the $y$-direction than the $x$-direction in case 1 . However, the flow penetration is similar in both directions in case 14. A uniform temperature (Figure 26b) can be seen at the mid-plane in case 1 due to the dominant effect of mixing. The high DR at the ankle level (i.e., $z^{*}=0.1 \mathrm{~m}$ ) is perhaps caused by the relatively high air velocity with a small nozzle diameter (Figure 26c, case 1). The temperature stratification increases (case 14) by increasing the nozzle diameter and number of nozzles because the mixing effect decreases. Interestingly, the 
designed supply device (case 14) achieved satisfactory temperature stratification.

$a$

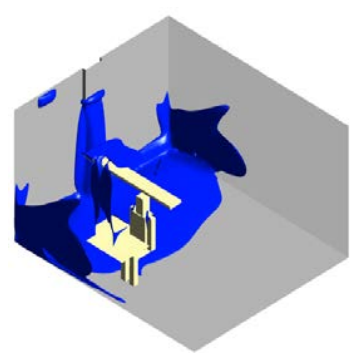

Case 1

$b$

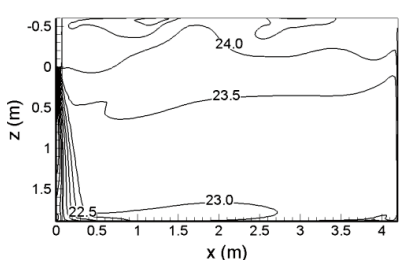

Case 1

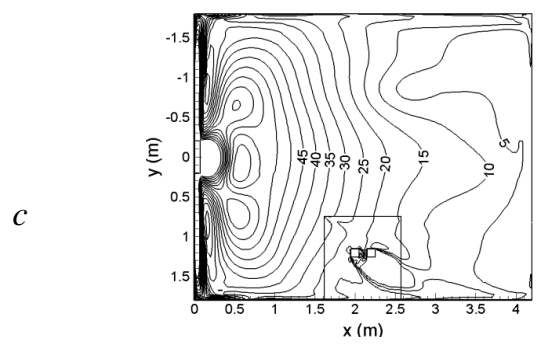

Case 1

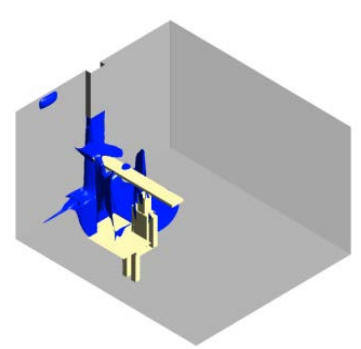

Case 14

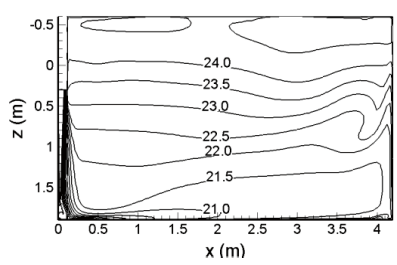

Case 14

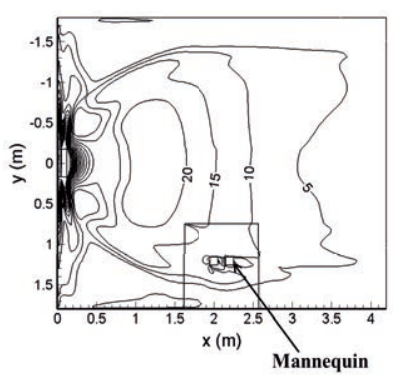

Case 14

Figure 26. Effects of the nozzle array configuration, nozzle diameter, number of nozzles, and inlet discharge height on the (a) iso-velocity contour plot at $0.25 \mathrm{~m} / \mathrm{s}$, (b) vertical temperature distribution, and (c) DR distribution at the ankle level.

According to Figure 26c (case 1), the DR at the ankle level is higher than $30 \%$ in some of the regions; this value is above the recommended value in ISO 7730 (2005) and ASHRAE Standard 55 (2004). The DR for case 14 with the most nozzles and a larger nozzle diameter is lower than that for case 1 , in which there were fewer nozzles and smaller nozzle diameters. As shown in Figure 26 (case 14), the DR are distributed within an acceptable range in most regions of the room (ASHRAE Standard 55, 2004) and are below $10 \%$ in the region where the mannequin is located. 
The vertical temperature difference within the occupied zone between the neck and ankle levels for a sitting $\left(\Delta T_{1.1-0.1}\right)$ and standing person $\left(\Delta T_{1.7-0.1}\right)$ are 0.3 and 0.6 for case 1 , while the values increase to 1.6 and 2.6 for case 14 , respectively. DR decreases from $22 \%$ for case 1 to $13 \%$ for case 14, and the average PPD within the occupied zone remained in the acceptable range (below 10\%). The heat removal effectiveness, $\varepsilon_{t}$, which is 1.15 for case 1 , increased to 1.34 for case 14 . Notably, the designed modified WCJ supply device fulfills the standard criteria. Investigation of the design parameters for an air supply device in terms of the ventilation performance can be found in detail in Paper IV. It can be concluded that the nozzle diameter and number of nozzles have a major impact on the distribution of air by the modified WCJ supply device, which affects the temperature stratification DR, PPD, and $\varepsilon_{t}$.

\subsubsection{Comparison study}

The ventilation performance of the proposed WCJ supply device (WCJSD) is compared numerically for the mixing supply device (MSD), displacement supply device (DSD) and impinging jet supply device (IJSD) in an office room.

The iso-velocity contour plots at $0.25 \mathrm{~m} / \mathrm{s}$ together with the temperature contour plots are shown for the supply devices in Figure 27. The iso-velocity of $0.25 \mathrm{~m} / \mathrm{s}$ is shown as a contour in Figure 27, where the colors represent the air temperature. As seen, the airflow pattern and temperature distribution of the WCJSD are very similar to the studied IJSD. In the WCJSD, the WCJ remains attached to the wall and moves downward until it reaches the floor. The wall jet across the floor is distributed radially after the stagnation region. The entrainment involved in the WCJSD is less than in the MSD. 

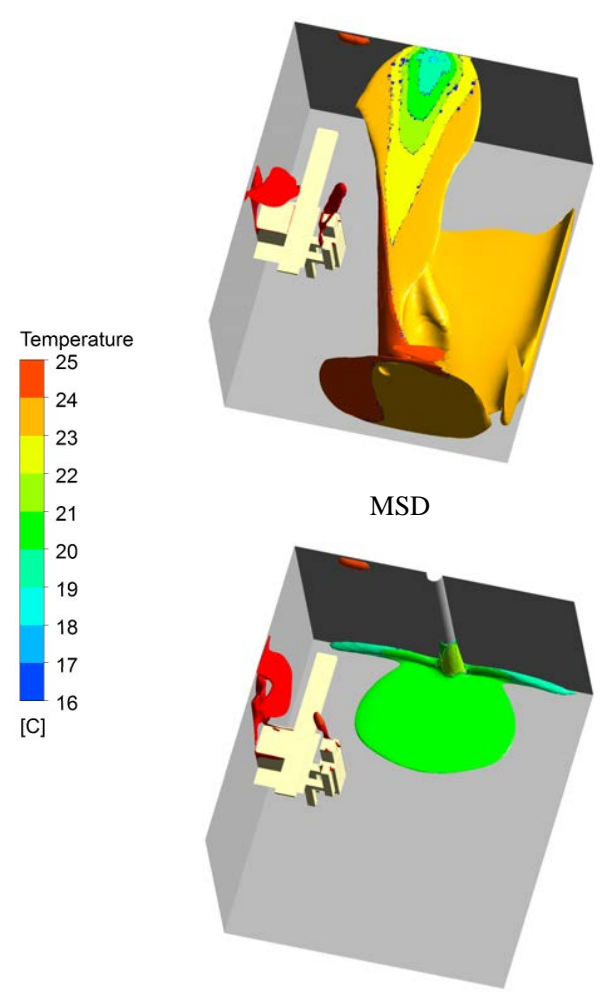

IJSD

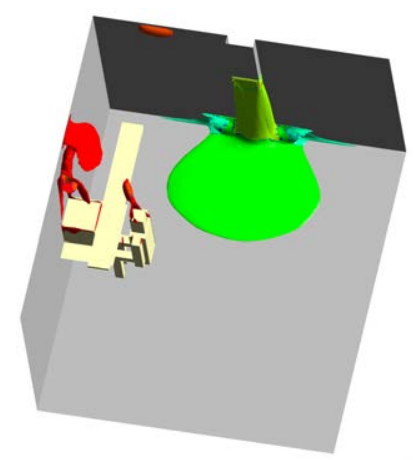

WCJSD

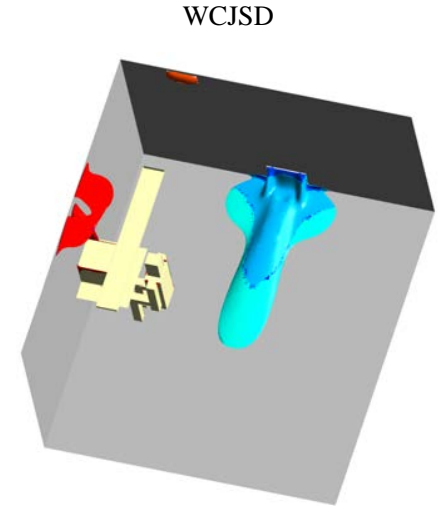

DSD

Figure 27. Iso-surface of the velocity of $0.25 \mathrm{~m} / \mathrm{s}$ together with its corresponding temperature contour plots for the MSD, WCJSD, IJSD, and $\operatorname{DSD}\left(Q=0.025 \mathrm{~m}^{3} / \mathrm{s}\right.$ and $\left.T_{\mathrm{s}}=16^{\circ} \mathrm{C}\right)$.

The vertical temperature distribution in the mid-plane for the MSD, WCJSD, IJSD, and DSD is shown in Figure 28. Thermal stratification is observed for the WCJSD; however, the uniform temperature distribution is enhanced for the MSD. No significant difference is observed in the contour plots of the temperature distribution for the WCJSD and IJSD. As the mixing effect is reduced, the vertical temperature difference increases, and a lower room air temperature will be provided. 


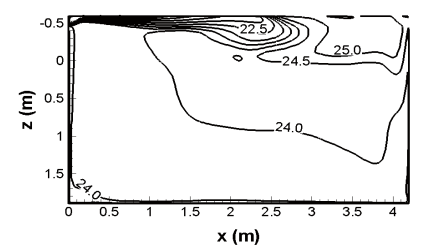

MSD

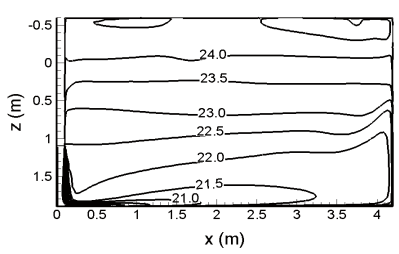

IJSD

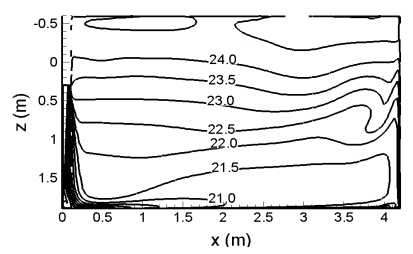

WCJSD

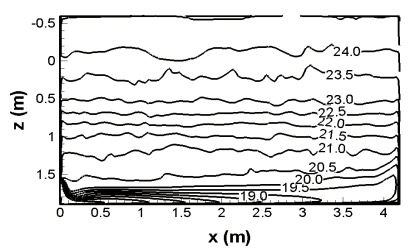

DSD

Figure 28. Vertical temperature distribution for the MSD, WCJSD, IJSD, and DSD.

In Table 2 ventilation performance of the WCJSD compared with the MSD, IJSD and DSD in terms of the thermal comfort and ventilation efficiency (i.e., heat removal and air change efficiency). As a result, the MSD provides the highest occupied zone temperature $\left(24.1^{\circ} \mathrm{C}\right)$, followed by the IJSD $\left(22.5^{\circ} \mathrm{C}\right)$, WCJSD $\left(22.3^{\circ} \mathrm{C}\right)$, and $\operatorname{DSD}\left(21.6^{\circ} \mathrm{C}\right)$. To fulfill the standard criteria, the temperature stratification should be below $3^{\circ} \mathrm{C}$ (ISO 7730, 2005) to avoid the aspect of occupied discomfort. The air temperature difference (i.e., $\Delta T_{1.1-0.1}$ and $\Delta T_{1.7-0.1}$ ) of the WCJSD is less than $3^{\circ} \mathrm{C}$, which is in the acceptable range according to ISO 7730 (2005). According to Table 2, the PPD value in the occupied zone is controlled below the threshold of $10 \%$ for the WCJSD (ISO 7730, 2005). DR is assessed as an average value at a height of $0.1 \mathrm{~m}$ above the floor in the occupied zone. The DR values are in the acceptable range, as recommended by ASHRAE Standard 55 (2004) and ISO 7730 (2005). As seen in Table 2, the value of $\varepsilon_{t}$, is 1.34 for the WCJSD, while MSD and DSD provide the lowest and highest $\varepsilon_{t}$ i.e., 1.04 and 1.46, respectively. As a result, more efficient heat removal is achieved by an increase in the stratified temperature distribution. The ventilation performance of the four devices with respect to the indoor air quality was further evaluated by the index of air exchange efficiency $\left(\varepsilon_{a}\right)$ based on the mean age of the air. The value of $\varepsilon_{a}$ for the WCJSD is between the values obtained from mixing and displacement (Table 2). 
5 Results and discussion

Table 2. Ventilation performance of the MSD, WCJSD, IJSD, and DSD.

\begin{tabular}{|c|c|c|c|c|c|c|}
\hline Supply device & $\begin{array}{c}\Delta T_{1.1-0.1} \\
\quad\left({ }^{\circ} \mathrm{C}\right)\end{array}$ & $\begin{array}{c}\Delta T_{1.7-0.1} \\
\left({ }^{\circ} \mathrm{C}\right)\end{array}$ & $\begin{array}{l}\text { DR } \\
(\%)\end{array}$ & $\begin{array}{c}\mathrm{PPD}_{\mathrm{oz}} \\
(\%)\end{array}$ & $\varepsilon_{\mathrm{t}}$ & $\varepsilon_{\mathrm{a}}$ \\
\hline$\overline{\text { MSD }}$ & 0.2 & 0.3 & 17 & 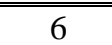 & 1.04 & 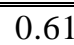 \\
\hline WCJSD & 1.6 & 2.6 & 13 & 9 & 1.34 & 0.67 \\
\hline IJSD & 1.6 & 2.4 & 12 & 9 & 1.29 & 0.7 \\
\hline DSD & 3.0 & 4.2 & 9 & 14 & 1.46 & 0.83 \\
\hline
\end{tabular}

The comparison for achieving the same occupied zone temperature of $24.2{ }^{\circ} \mathrm{C}$ shows that the WCJSD requires a slightly higher airflow rate (1.06 times) and fan power (1.18 times) than the DSD, but it is more energy efficient than the MSD. Comparisons of the ventilation performance for further case studies can be found in Paper V. 


\section{Conclusions}

In this thesis, the ventilation performances of the conventional wall confluent jets (WCJ), modified WCJ, and impinging confluent jets (ICJ) supply devices were investigated experimentally in an office mock-up and an industrial premises. The numerical study that was performed consisted of a validation study, parametric study and comparison study for the modified WCJ supply device.

The results reveal that the WCJ remains attached to the inlet wall due to the Coanda effect. It is notable that the thickness of the WCJ grows and becomes wider for the conventional WCJ supply device compared to the modified WCJ supply device, which indicates a greater entrainment of the room air with its surrounding air. The results show that the modified WCJ supply device operating at a lower airflow rate can provide acceptable thermal comfort for the occupant, and it corresponds to less fan power and saves energy compared to the conventional WCJ supply device.

The study of the flow field of the modified WCJ confirms the appearance of two regions, i.e., the primary and secondary jet regions. A primary WCJ is formed below the supply device with its axis along the inlet wall, and a secondary wall jet is created along the floor after a stagnation region. The numerical predictions of three turbulence models (renormalization group (RNG $k-\varepsilon$ ), realizable (Re $k-\varepsilon$ ), and shear stress transport (SST $k-\omega)$ ) are compared by velocity and temperature measurement of the primary and secondary wall jets. The numerical predictions accomplished by the SST $k-\omega$ model provide the best agreement with the experimental results. Therefore, the SST $k-\omega$ model was used to investigate further the ventilation performance of the modified WCJ supply device. 
Impacts of different configurations of the supply device on the ventilation performance show that the flow pattern is strongly dependent on the nozzle diameter and number of nozzles. The flow behavior is nearly independent of the inlet discharge height and configuration of the nozzle array for the studied range.

The results from the comparison study show that the present proposed WCJ can provide an acceptable thermal environment and removes excess heat more efficiently than the mixing supply device (MSD). The WCJ supply device has the combined positive effects of both mixing and stratification principles. Comparisons for achieving the same occupied zone temperature show that the WCJ requires a slightly higher airflow rate and fan power than DSD, but that it is more energy efficient than the MSD. Results of comparison study show that WCJ device can provide an acceptable and overall ventilation performance. This study is for a certain types of mixing and displacement supply devices and specific room conditions, further studies is required to derive more general conclusions of these supply devices.

The study of the ICJ supply device shows good indoor thermal comfort conditions in the occupied zone by creating a well-distributed airflow. In the studied premises, the ICJ covers to a great extent heating and cooling demand during the cold and hot seasons. 


\section{Suggestions for future work}

The studied topics within this thesis have spawned interesting questions that are important to investigate further. To fully evaluate the ventilation performance of supply devices, it is interesting to study the configurations and locations of the supply devices in different types of built environments. Another topic of great interest is to perform a building energy simulation and to conduct a qualitative study, such as with questionnaires. Further investigations need to be performed to obtain a comprehensive comparison between different ventilation supply devices. The effect of using a Variable Air Volume (VAV) system on the ventilation performance would be of great interest to study, while the Constant Air Volume (CAV) system was applied in the present study. Numerical studies of ICJ supply devices need to be conducted in order to gain a thorough understanding of the flow behavior of the system.

Configurations of modified WCJ supply devices and their ventilation performance can be further examined with the use of mathematical and statistical techniques, to provide systematic parametric studies. The simultaneous effect of changes in two or more design factors can be studied to investigate the impact of a number of factors and the interaction between them on the flow field development while focusing on the thermal comfort and ventilation efficiency in the occupied zones. The large number of required experiments, which increase the cost of an investigation, can be reduced using this technique.

The location of the supply devices is another aspect that need to be further investigated. Different positions (e.g., corners) and different heights (e.g., near the floor) of modified WCJ and ICJ in different types of built environments can be further studied. The key concept is to evaluate the impact of different locations for the supply devices on the ventilation performance. 
Qualitative case studies with a questionnaire could be useful to gather information that is related to the occupants' comfort (i.e., occupants' draught discomfort, PMV and PPD) and air quality. It is vital to increase people's awareness about the consequences of poor air quality and the occupants' comfort with respect to their health. The questions included in the questionnaire would be selected to gain future solutions for controlling the indoor environment. The results obtained from a questionnaire can be compared with measurements and numerical predictions.

The ventilation performance and energy usage of the modified WCJ and ICJ supply devices can be studied further by evaluating ADI and building an energy simulation model. It is of great interest to predict or forecast the future or present energy use.

The performance of the modified WCJ and ICJ in different built environments (such as office rooms, classrooms or industrial premises) would be interesting to study, with respect to the ventilation systems that are applied with the purpose of heating and cooling a building. A complete study could be conducted for different heating and cooling loads in a building with different inlet boundary conditions.

The use of a VAV system could have the potential of being an effective way of reducing energy use in heating, ventilation and air conditioning within a building. The studies presented within this thesis could be further extended by performing unsteady state CFD simulations in more detail, to capture the transient behavior of the flow and gain a thorough understanding of the ventilation systems. 


\section{References}

Adrian, R.J., Westerweel, J., 2010. Particle image velocimetry. Cambridge University Press.

Airpak, 3.0, 2007. User's guids. Fluent Inc.

ANSYS, 2010. Fluent theory guide, ANSYS Inc.

ANSYS, 2012. Fluent theory guide, ANSYS Inc.

ASHRAE, 2009a. Handbook of fundamentals. Ch 9: Thermal comfort.

ASHRAE, 2009b. Handbook of fundamentals. Ch 13: Indoor environmental modeling

ASHRAE, 2009c. Handbook of fundamentals. Ch 36: Measurement and instruments.

ASHRAE Standard 55, 2004. Thermal environmental conditions for human occupancy american society of heating, refrigerating and airconditioning engineers.

Awbi, H.B., 1989. Application of computational fluid dynamics in room ventilation. Building and Environment 24, 73-84.

Awbi, H.B., 1998. Energy efficient room air distribution. Renewable Energy 15, 293-299.

Awbi, H.B., 2003. Ventilation of Buildings. Spon Press, London.

Awbi, H.B., 2008. Ventilation systems, design and performance. Taylor \& Francis.

Blomqvist, C., Sandberg, M., 1997. Measurements and control or air mothions within a building. Proceeding of the 18th annual AIVC conference, Athens, Greece.

Boutier, A., 2012. Laser Velocimetry in Fluid Mechanics. Wiley.

Bruun, H.H., 1995. Hot-wire anemometry-principles and signal analysis Oxford University Press, New York, NY. 
Cao, G., Awbi, H., Yao, R., Fan, Y., Sirén, K., Kosonen, R., Zhang, J., 2014. A review of the performance of different ventilation and airflow distribution systems in buildings. Building and Environment 73, 171-186.

Cao, G., Ruponen, M., Kurnitski, J., 2010. Experimental investigation of the velocity distribution of the attached plane jet after impingement with the corner in a high room. Energy and Buildings 42, 935-944.

Causone, F., Baldin, F., Olesen, B.W., Corgnati, S.P., 2010. Floor heating and cooling combined with displacement ventilation: Possibilities and limitations. Energy and Buildings 42, 2338-2352.

Cehlin, M., Moshfegh, B., 2010. Numerical modeling of a complex diffuser in a room with displacement ventilation. Building and Environment 45, 2240-2252.

Cehlin, M., Moshfegh, B., Sandberg, M., 2000. Visualization and measuring of air temperature based on infrared thermography. Proceeding of the 7th International Conference on Air Distribution in Rooms (Roomvent).

Cehlin, M., Moshfegh, B., Sandberg, M., 2002. Measurements of air temperatures close to a low-velocity diffuser in displacement ventilation using an infrared camera. Energy and Buildings 34, 687-698.

Chen, H., Janbakhsh, S., Larsson, U., Moshfegh, B., 2015. Numerical investigation of ventilation performance of different air supply devices in an office environment. Building and Environment 90, 37-50.

Chen, Q., 1996. Prediction of room air motion by Reynolds-stress models. Building and Environment 31, 233-244.

Chen, Q., 2009. Ventilation performance prediction for buildings: A method overview and recent applications. Building and Environment 44, 848-858.

Chen, Q., Srebric, J., 2001. Simplified diffuser boundary condition for numerical room airflow models. ASHRAE RP-1009.

Chen, Q., Van Der Kooi, J., 1990. A methodology for indoor airflow computations and energy analysis for a displacement ventilation system. Energy and Buildings 14, 259-271.

Chen, Q., Zhai, Z., 2004. The use of CFD tools for indoor environmental design. Advanced Building Simulation, eds. A. Malkawi and G. Augenbroe. New York: Spon Press, 119-140. 
Cheong, K.W.D., Yu, W.J., Kosonen, R., Tham, K.W., Sekhar, S.C., 2006. Assessment of thermal environment using a thermal manikin in a field environment chamber served by displacement ventilation system. Building and Environment 41, 1661-1670.

Cho, Y., Awbi, H.B., Karimipanah, T., 2008. Theoretical and experimental investigation of wall confluent jets ventilation and comparison with wall displacement ventilation. Building and Environment 43, 1091-1100.

Davidson, L., Nielsen, P.V., 1996. Large eddy simulations of the flow in a three-dimensional ventilated room. Proceedings of Roomvent 1996 2:161-68.

Elvsén, P.-Å., Sandberg, M., 2009. Buoyant jet in a ventilated room: Velocity field, temperature field and airflow patterns analysed with three different whole-field methods. Building and Environment 44, 137-145.

Emmerich, S., McGrattan, K., 1998. Application of a large eddy simulation model to study room air-flow. ASHRAE Transactions 104(1), $1-9$.

Etheridge, D., Sandberg, M., 1996. Building Ventilation: Theory and Measurement.

Fanger P.O., 1973. Thermal comfort. McGraw-Hill, New York.

Fanger, P.O., 2000. Provide good air quality for people and improve their productivity. Proceedings of Roomvent. Reading, UK.

Fingerson, L.M., 1994. Thermal anemometry, current state, and future directions. Review of Scientific Instruments 65, 285-300.

Fisk, W.J., Rosenfeld, A.H., 1997. Estimates of Improved Productivity and Health from Better Indoor Environments. Indoor Air 7, 158-172.

Freitas, C.J., 2002. The issue of numerical uncertaintly. Applied Mathematical Modelling 26, 237-248.

Ghahremanian, S., 2014. A near-field study of multiple interacting jets: Confluent jets. Doctoral thesis, Dissertation No.1639, Department of Management and Engineering. Linköping University.

Ghahremanian, S., Moshfegh, B., 2013. Evaluation of RANS models in predicting low reynolds, free, turbulent round jet. Journal of Fluids Engineering 136, 011201-011213.

Ghahremanian, S., Moshfegh, B., 2014a. A study on proximal region of low Reynolds confluent jets Part 1: Evaluation of turbulence models in 
prediction of inlet boundary conditions. ASHRAE Transactions 120, Part 1, NY-14-021.

Ghahremanian, S., Moshfegh, B., 2014b. A study on proximal region of low Reynolds confluent jets, Part 2: Numerical prediction of the flow field. ASHRAE Transactions 120, Part 1, NY-14-022.

Ghahremanian, S., Svensson, K., Tummers, M., Moshfegh, B., 2014a. Near-field development of a row of round jets at low Reynolds numbers. Experiments in Fluids 55, 1-18.

Ghahremanian, S., Svensson, K., Tummers, M.J., Moshfegh, B., 2014b. Near-field mixing of jets issuing from an array of round nozzles. International Journal of Heat and Fluid Flow 47, 84-100.

Goodfellow, H., Tähti, E., 2001. Industrial ventilation design guidebook, Academic press.

Gosman, A.D., Nielsen. PV, Restivo, A., Whitelaw, J., 1980. The flow properties of rooms with small ventilation opening. Journal of Fluid Engineering 102, 316-323.

Hassani, V., Stetz, M., 1994. Application of infrared thermography to room air temperature measurements. ASHRAE Transactions Part 2, 1238-1247.

Hawkins, A.N., Hosni, M., Jones, B., 1995. A comparison of room air motion in a full size room using different diffusers and opening conditions. ASHRAE Transactions 101, 81-100.

Hinze, J., 1975. Turbulence, 2nd ed. McGraw-Hill.

ICEPAK4.4, 2007. User's guids. Fluent Inc.

ISO 7730, 2005. Ergonomics of the thermal environment-analytical determination and interpretation of thermal comfort using calculation of PMV and PPD indices and local thermal comfort criteria.

Janbakhsh, S., Moshfegh, B., 2009. Experimental investigation of a new supply diffuser in an office room, Proceedings of 11th International Conference on Air Distribution in Rooms. ROOMVENT 2009, Busan, Korea.

Janbakhsh, S., Moshfegh, B., 2014a. Experimental investigation of a ventilation system based on wall confluent jets. Building and Environment 80, 18-31.

Janbakhsh, S., Moshfegh, B., 2014b. Numerical study of a ventilation system based on wall confluent jets. HVAC\&R Research 20, 846-861. 
Janbakhsh, S., Moshfegh, B., 2015. Investigation of design parameters for an air supply device based on wall confluent jets. Submitted for journal publication.

Janbakhsh, S., Moshfegh, B., Ghahremanian, S., 2010. A newly designed supply diffuser for industrial premises. International Journal of Ventilation 9, 59-68.

Jiang, Y., Chen, Q., 2001. Study of natural ventilation in building by large eddy simulation. Journal of Wind Engineering and Industrial Aerodynamics 89(13), 1155-1178.

Johnson, R.W., 1998. The handbook of fluid dynamics. CRC Press LLC.

Jones, P.J., Whittle, G.E., 1992. Computational fluid dynamics for building air flow prediction--current status and capabilities. Building and Environment 27, 321-338.

Karimipanah, T., Awbi, H.B., 2002. Theoretical and experimental investigation of impinging jet ventilation and comparison with wall displacement ventilation. Building and Environment 37, 1329-1342.

Karimipanah, T., Awbi, H.B., Moshfegh, B., 2008. The air distribution index as an indicator for energy consumption and performance of ventilation systems. Journal of Human-Environmental system 11(20), 7784.

Karimipanah, T., Awbi, H.B., Sandberg, M., Blomqvist, C., 2007. Investigation of air quality, comfort parameters and effectiveness for two floor-level air supply systems in classrooms. Building and Environment 42, 647-655.

Karimipanah, T., Moshfegh, B., 2007. On the performance of confluent jets ventilation system in office space, Proceedings of Roomvent, 10th International Conference on Air Distribution in Rooms., Helsinki, Finland.

Krajč́k, M., Simone, A., Olesen, B.W., 2012. Air distribution and ventilation effectiveness in an occupied room heated by warm air. Energy and Buildings 55, 94-101.

Ladeinde, F., Nearon, M., 1997. CFD applications in the HVAC \& R industry ASHRAE Journal 39 (1):44.

Lee, C.K., Lam, H.N., 2007. Computer modeling of displacement ventilation systems based on plume rise in stratified environment. Energy and Buildings 39, 427-436. 
Lee, H., Awbi, H.B., 2004. Effect of internal partitioning on indoor air quality of rooms with mixing ventilation-basic study. Building and Environment 39, 127-141.

Li, Y., Sandberg, M., Fuchs, L., 1992. Vertical Temperature Profiles in Rooms Ventilated by Displacement: Full-Scale Measurement and Nodal Modelling. Indoor Air 2, 225-243.

Lin, Z., 2011. Effective draft temperature for evaluating the performance of stratum ventilation. Building and Environment 46, 1843-1850.

Lundström, H., Blomqvist, C., Jonsson, P., Pettersson, I., 1990. A microprocessor-based anemometer for low air velocities., Proceedings of Roomvent, Oslo, Norway.

Luo, S., Roux, B., 2004. Modeling of the HESCO nozzle diffuser used in IEA Annex-20 experiment test room. Building and Environment 39, 367384.

Mathisen HM., 1989. Case studies of displacement ventilation in public Halls. ASHRAE Transactions 95, 1018-1027.

Mattsson, M., 1999. On the efficiency of displacement ventilation - with particular reference to the influence of physical activity. Doctoral thesis, Dissertation No.1639

KTH built environment, Stockholm, ISBN 91-628-3674-9.

McIntyre, D.A., 1980. Indoor climate, applied science publishers, London.

Melikov, A., Pitchurov, G., Naydenov, K., Langkilde, G., 2005. Field study on occupant comfort and the office thermal environment in rooms with displacement ventilation. Indoor Air 15, 205-214.

Melikove, A.K., Popiolek, Z. Silva, M.C.G. Care, I., 2007. Accuracy limitations for low-velocity measurements and draft assessment in rooms. HVAC \& R Research 13, 971-986.

Menter, F.R., 1994. Two-equation eddy-viscosity turbulence models for engineering applications. AIAA Journal 32, 1598-1605.

Müller, D., Kandzia, C., Kosonen, R., Melikov, A.K., Nielsen Peter, V., 2013. Mixing ventilation-guidebook on mixing air distribution design. No.19.

Musser, A., McGrattan, K., 2002. Evaluation of a fast large-eddysimulation model for indoor air-flows. Journal of Architectural Engineering 8(1), 10-18. 
Nielsen, P., 1992. Description of supply openings in numerical models for room air distribution. ASHRAE Transactions 98, 963-971.

Nielsen, P., 1993. Displacmenet ventilation- theory and design. Department of building technology and structural engineering, Aalborg University, ISSN 0902-8002, U9306.

Nielsen, P., 1997. The box method-a practical procedure for introduction of an air supply devices in CFD calculation, . Department of Building Technology \& Structural Engineering, Aalborg University.

Nielsen, P., 2004. Computational fluid dynamics and room air movement. Indoor Air 14, 134-143.

Nielsen, P., 2007. Analysis and design of room air distribution systems. HVAC\&R Research Journal 13 (6), 987-997

Nielsen, P.V., 1974. Flow in air conditione rooms. Doctoral thesis. Danishe Technical University.

Nielsen, P.V., 1975. Prediction of air flow and comfort air conditioned spaces. ASHRAE Transactions 81, 247:259.

Nielsen, P.V., 1998. The selection of turbulence models for prediction of room airflow. ASHRAE Transactions 104, 1119-1127.

Nielsen, P.V., 2000. Velocity distribution in a room ventilated by displacement ventilation and wall-mounted air terminal devices. Energy and Buildings 31, 179-187.

Nielsen, P.V., Allard, F., Awbi, H.B., Davidson, L., Schälin, A., 2007. Computational fluid dynamics in ventilation design. REHVA Guidebook.

Palonen, J., Majanen, A., Seppänen, O., 1991. Performance of displacement air distribution in an office room. Environment International 17, 303-309.

Pan, C.-S., Chiang, H.-C., Yen, M.-C., Wang, C.-C., 2005. Thermal comfort and energy saving of a personalized PFCU air-conditioning system. Energy and Buildings 37, 443-449.

Raffel, M., Willert, C.E., Wereley, S.T., Kompenhans, J., 2007. Particle image velocimetry: A practical guide. Springer.

Rohdin, P., Moshfegh, B., 2007. Numerical predictions of indoor climate in large industrial premises. A comparison between different $k-\varepsilon$ models supported by field measurements. Building and Environment 42, 38723882. 
Sagaut, P., 2002. Large eddy simulation for incompressible flow. Springer Verlag.

Sandberg, M., 1981. What is ventilation efficiency? Building and Environment 16, 123-135.

Sandberg, M., 2007. Whole-field measuring methods in ventilated rooms. HVAC\&R Research 13, 951-970.

Sandberg, M., Blomqvist, C., Sjöberg, M., 1986. Efficiency of general ventilation systems in residential and office buildings- concepts and measurements. In: Goodfellow HD, editor. Ventilation 85. Elsevier Science Publishers B.V. Amsterdam- printed in the Netherlands.

Sandberg, M., Lundström, H., Nilsson, O., Stymne, H., 2008. Experimental methods in ventilation. Advances in Building Energy Research 2, 159-210.

Sayigh, A., 2013. Sustainability, energy and architecture: Case studies in realizing green buildings. Elsevier Science.

Sforza, P.M., Herbst, G., 1970. A study of three-dimensional, incompressible, turbulent wall jets. AIAA Journal 8(2), 276-283.

Shih, T., Liou W, Shabbir, A., Yang, Z., Zhu, J., 1995. A new k-e eddy viscosity model for high reynolds number turbulent flows-Model Development and Validation. Computers \& Fluids 24, 227-238.

Skovgaard, K., Nielsen, P., 1991. Modeling complex inlet geometries in CFD-Applied to air flow in ventilation rooms, Proceedings of the 12th AIVC Conference, Ottawa, Canada.

Sørensen, D.N., Nielsen, P.V., 2003. Quality control of computational fluid dynamics in indoor environments. Indoor Air 13, 2-17.

Srebric, J., Chen, Q., 2002. Simplified numerical models for complex air supply diffusers. International Journal of HVAC\&R Research 8, 277-294.

Stamou, A., Katsiris, I., 2006. Verification of a CFD model for indoor airflow and heat transfer. Building and Environment 41, 1171-1181.

Stetz, M., 1993. Characterizing cold jets and diffuser performace via infrared thermography. M.S. thesis, Fort Collins, Colorado State University, USA.

Sun, Y., Smith, T.F., 2005. Airflow characteristics of a room with square cone diffusers. Building and Environment 40, 589-600. 
Sundberg, J., 1993. Use of thermography to register air temperatures in cross sections of rooms and to visualize the airflow from air-supply diffusers. Thermosense XV, Orlando, FL 1933, 61-66, SPIE.

Svensson, K., Ghahremanian, S., Moshfegh, B., Tummers, M., 2012. Numerical and Experimental investigation of flow behaviour in a confluent jet ventilation system for industrial premises. Proceedings of the 10th International Conference on Industrial Ventilation, Paris.

Svensson, K., Rohdin, P., Moshfegh, B., Tummers, M.J., 2014. Numerical and experimental investigation of the near zone flow field in an array of confluent round jets. International Journal of Heat and Fluid Flow 46, 127-146.

Törnström, T., 2003. Numerical predictions and measurement of nonisothermal airflows, evaluation of buoyant wall jets and airflow through large openings. LiU-TEK-LIC-2003:58.

Versteeg, H.K., Malalasekera, W., 2007. An introduction to computational fluid dynamics - The finite volume method. Prentice Hall, England.

Viets, H., Sforza, P.M., 1966. An experimental investigation of a turbulent incompressible three-dimensional wall jet. Polytechnic Institute of Brooklyn

Wargocki , P., 1998. Human perception, productivity and symptoms related to indoor air quality. Technical University of Denmark, Denmark, ISBN 87-7475-201-4.

Wigö, H., Sandberg, M., 2002. Creating velocity variations in a whole room. Proceeding of 8th international conference on air distribution in rooms, 273-276.

Wigö, H., Sandberg M., 2001 Velocity variations in ventilated rooms as a method for creating comfort, Proceedings 22nd AIVC Conference.

Williams, P.T., Baker, A., Kelso, R., 1994a. Numerical calculation of room air motion- Part 3: three-dimensional CFD simulation of a full-scale room air experiment. ASHRAE Transactions 100, 549- 564.

Williams, P.T., Baker, A., Kelso, R., 1994b. Numerical calculation of room air motion-part 2 : the continuity constraint finite element method for three-dimensional incompressible thermal flows. ASHRAE Transactions 100, 531- 548.

Yakhot, V., Orszag, S., 1986. Renormalization group analysis of turbulence. Journal of Scientific Computing 1:3-51. 
Zhai, Z., 2006. Application of CFD in building design: Aspects and trends. Indoor and Built Environment 15, 305-313.

Zhai, Z., Zhang, Z., Zhang, W., Chen, Q., 2007. Evaluation of various turbulence models in predicting airflow and turbulence in enclosed environments by CFD: Part 1-Summary of prevalent turbulence models. HVAC \& R Research 13 (6) 853-870

Zhang, Z., Zhang, W., Zhai, Z., Chen, Q., 2007. Evaluation of various turbulence models in predicting airflow and turbulence in enclosed environments by CFD: Part 2-comparison with experimental data from literature. HVAC\&R Research 13 (6), 871-886

Zhivov, A.M., Case, M., Liesen, R., Kimman, J., Broers, W., 2014. Energy Master Planning Towards Net-Zero Energy Communities/Campuses. ASHRAE Transactions 120, Part 1, NY-14-010, 114-129. 


\section{Papers}

The articles associated with this thesis have been removed for copyright reasons. For more details about these see:

http://urn.kb.se/resolve?urn=urn:nbn:se:liu:diva-117442 